\title{
Metallic Reflector-Based X-Band Circularly Polarized Hollow Dielectric Resonator Antenna for High Gain in UWB Applications
}

SACHIN KUMAR YADAV ( $\square$ yadav_sachinyadav@yahoo.com )

Thapar Institute of Engineering and Technology https://orcid.org/0000-0002-1455-5280

Amanpreet Kaur

Thapar Institute of Engineering and Technology

Rajesh Khanna

Thapar Institute of Engineering and Technology

\section{Research Article}

Keywords: Defective ground structure, circularly polarized antenna, Hollow dielectric resonator antenna, Ultra-wideband antenna, parasitic metallic strips, metallic reflector and Quarter wave transformer feedline.

Posted Date: March 16th, 2021

DOI: https://doi.org/10.21203/rs.3.rs-280077/v1

License: (9) This work is licensed under a Creative Commons Attribution 4.0 International License. Read Full License 


\title{
Metallic reflector-based X-band Circularly Polarized Hollow Dielectric Resonator Antenna for high gain in UWB Applications
}

\author{
Sachin Kumar Yadav ${ }^{1, *}$, Amanpreet Kaur ${ }^{2}$, Rajesh Khanna ${ }^{3}$ \\ 1,2,3 Electronics and Communication Engineering Department \\ 1,2,3 Thapar Institute of Engineering \& Technology (Deemed to be University), Patiala, India \\ 1'yadav_sachinyadav@yahoo.com
}

\begin{abstract}
A circularly polarized hollow dielectric resonator antenna (CPHDRA) is designed for X-band applications. Rectangular dielectric resonator (RDR) is used as a radiator element, fed by a quarter-wave transformer (QWT) feedline. By performance of the RDR antenna, an air cylindrical rod structure is extracted from RDR to enhance the gain and impedance bandwidth. Two parasitic strips are placed on the top of the RDR to achieve circular polarization with reported $\leq 3-\mathrm{dB}$ axial ratio (AR) bandwidth for X-band applications. In this article, UWB antenna covers range from 2.74 to $10.4 \mathrm{GHz}$ by using asymmetrical defective ground structure (DGS). In near field of the dielectric resonator, three different radiating modes namely $\mathrm{HE}_{11 \delta}, \mathrm{HE}_{21 \delta}, \mathrm{HE}_{23 \delta}$, and $\mathrm{HE}_{32 \delta}$ are at 4.4, 6, 8.8, and $9.9 \mathrm{GHz}$. For the generation of circular polarization (CP), two orthogonal modes are generated at 8.8 and $9.9 \mathrm{GHz}$ as per $\mathrm{XZ}$ and $\mathrm{YZ}$ planes. It has reported $23.8 \%$ (8 to $10.1 \mathrm{GHz}$ ) of 3 -dB AR bandwidth. The simulated and measured impedance bandwidths are $118.46 \%$ and $121.12 \%$ along with a peak gain of $6.55 \mathrm{~dB}$ without the use of a metallic reflector. By using a metallic reflector suspended in the bottom side of the substrate with a distance of $13.1 \mathrm{~mm}$ is reported along with the peak gain of $9.8 \mathrm{dBi}$.

KEYWORDS: Defective ground structure, circularly polarized antenna, Hollow dielectric resonator antenna, Ultra-wideband antenna, parasitic metallic strips, metallic reflector and Quarter wave transformer feedline.
\end{abstract}

\section{Introduction}

The Federal Communications Commission (FCC) has declared frequency for the unlicensed band from 3.1 to $10.6 \mathrm{GHz}$ in 2002 [1] and this range popular by name of Ultra-Wideband (UWB). The UWB systems have $7.5 \mathrm{GHz}$ of bandwidth which gained enormous importance in the last two decades. It is an open platform for users to use the band without any cost. It is more useful for shorter distance and implemented for academic and industrial telecommunication applications. UWB system has low power consumption with high data rate applications in short range. So, it is highly applicable in wireless communication, microwave imaging systems, satellite systems, and RADAR. Dielectric resonator antenna (DRA) [2-3] is included for the UWB application because it has several features over the metallic patch antenna [4].

Alternatively, dielectric resonators (DR) is worked as energy storage, so it has been applied in microwave circuit's to use as filters and oscillators. Further, the DRA characteristics depend on the electrical permittivity $\left(\varepsilon_{\mathrm{DR}}\right)$ of DR between 9 to 100 . If DR has low electrical permittivity with low $Q$ factor vice versa to give widen bandwidth. DRA has outstanding characteristics like ease to excitation, low cost, high radiation efficiency, low surface losses, and a compact antenna with widen bandwidth, less conduction losses [5-9] that are the advantages over microstrip patch antenna. Different shapes of the DRA are reported in the literature survey [9-14], and also introduced hollow rectangular DRA (HRDRA) have mechanically simple lightweight with several characteristics and proposed in 1993 [15-16].

The HRDRA has been attracted to the researchers due to several advantages as compared to the solid DRA, the hollow region of DR, decreases the effective permittivity and Q, lieu of impedance bandwidth and gain of the antenna is enhanced [16]. In hollow DRA has easily built the active and passive component for microwave circuits without any disturbance. Many 
wideband CP DRA has been reported and CP is achieved by using techniques of single/dual feeding [17], the shape of slot [18], metallic strips using in the DR surface [19-20], and innovative shape of DR [21]. In the hollow DRA field, to achieve the CP, many techniques are developing for the preclusion of losses with the linear polarized antenna [22-24]. Today, the researchers are working on the area of UWB hollow DRA with circular polarization (CP) properties.

In this communication, proposed circularly polarized hollow dielectric resonator antenna (CPHDRA) delivers the finest resolution for all the aforesaid problems. CPHDRA is fed by QWT microstrip feedline covering the frequency from 2.74 to $10.4 \mathrm{GHz}$. The antenna is made on Rogers RT 5880 substrate material with a permittivity of 2.2 and the asymmetrical DGS cut in ground plane and it is fixed on the bottom side of the substrate. Further metallic rectangular parasitic strips (MRPS) are fixed on DR layer to achieve $\leq 3-\mathrm{dB}$ AR bandwidth $23.8 \%$ (7.9 to $9.9 \mathrm{GHz})$.

\section{Antenna configuration}

Figure 1 $(a-b)$ shows the simulated different views of the proposed CPHDRA. Hollow shaped DRA is used to achieve the antenna performance in term of gain and impedance bandwidth in [14], a solid cylindrical shaped DR having a diameter of $2 \mathrm{D}_{\mathrm{a}}=8 \mathrm{~mm}$ is extracted from rectangular DR for improving gain as well as impedance bandwidth of the antenna, according to perturbation theory, it is explained in the next subsection. The DR consists of material $\mathrm{Al}_{2} \mathrm{O}_{3}$ with $\varepsilon_{\mathrm{DR}}=9.8$, thickness $\mathrm{h}_{\mathrm{dr}}=4 \mathrm{~mm}$, excited by a QWT feedline printed on top of the substrate (size $\left.50 \times 40 \times 0.8 \mathrm{~mm}^{3}\right) \varepsilon_{\mathrm{s}}=2.2$ and ground plane $\left(\mathrm{P}_{1}\right.$ to $\left.\mathrm{P}_{8}\right)$ with an asymmetric DGS $\left(\mathrm{G}_{1}, \mathrm{G}_{2}, \mathrm{G}_{3}=20\right.$, and $\left.\mathrm{G}_{4}\right)$ for improving the impedance bandwidth has been fixed at the bottom layer of the substrate. Two metallic strips are fixed on the top of the DR surface $\left(\mathrm{Ps}_{1} \times\right.$ Ps 2 , Ps $3 \times$ Ps4). These MRPS are applied with specific purpose of achieving CP in Xband. It also generates orthogonal components of the ' $\mathrm{E}$ ' field to achieve the circularly polarized waves (axial Ratio $\leq 3 \mathrm{~dB}$ ) cover the range from 8 to $10.1 \mathrm{GHz}$ for $\mathrm{X}$-band application. The CPHDRA optimized dimensions are mentioned in Table $1, \mathrm{P}_{1}$ to $\mathrm{P}_{8}$ show the metallic ground plane and $G_{1}$ to $G_{4}$ show the DGS part. In DRA, a metallic reflector is used to achieve the high gain of the antenna with maintained AR bandwidth $\leq 3 \mathrm{~dB}$. The size of the metallic reflector has been shown in Figure $1(b, d)$. A rectangular metallic reflector $(\operatorname{Ref} 1=75$, $\operatorname{Ref} 2=60$ ) is designed and fixed at a height of $\mathrm{Hr}(13.1 \mathrm{~mm})$ from the ground plane for high gain applications.

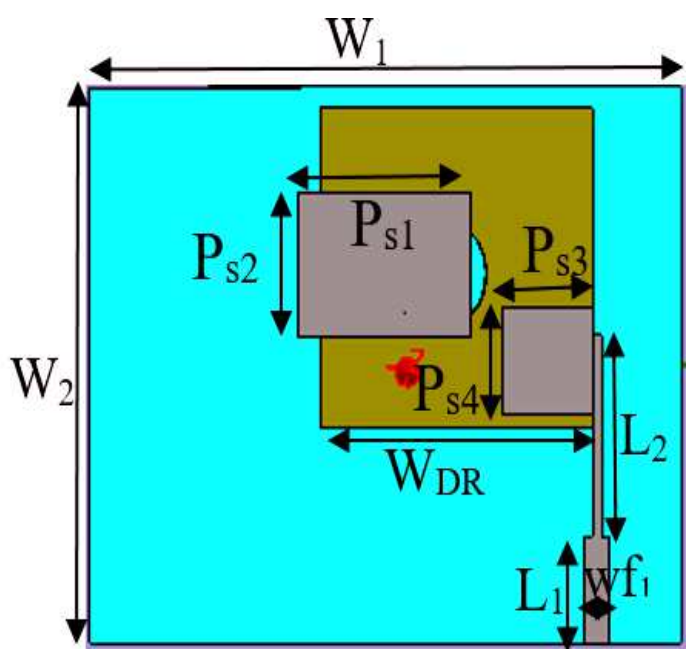

(a)

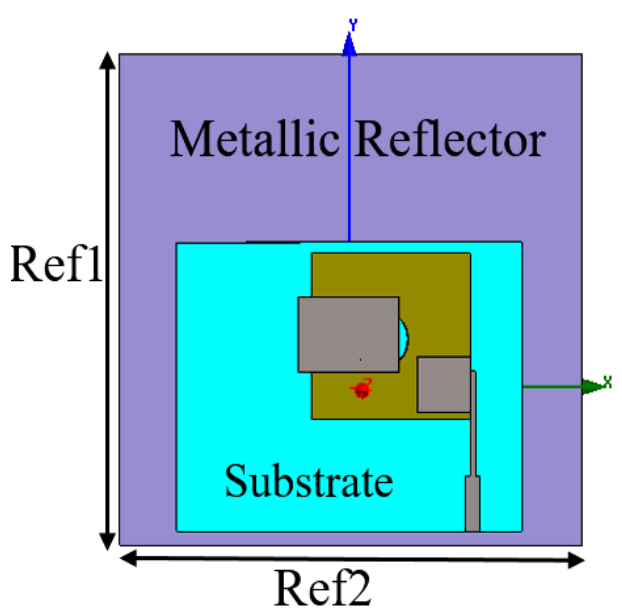

(b) 


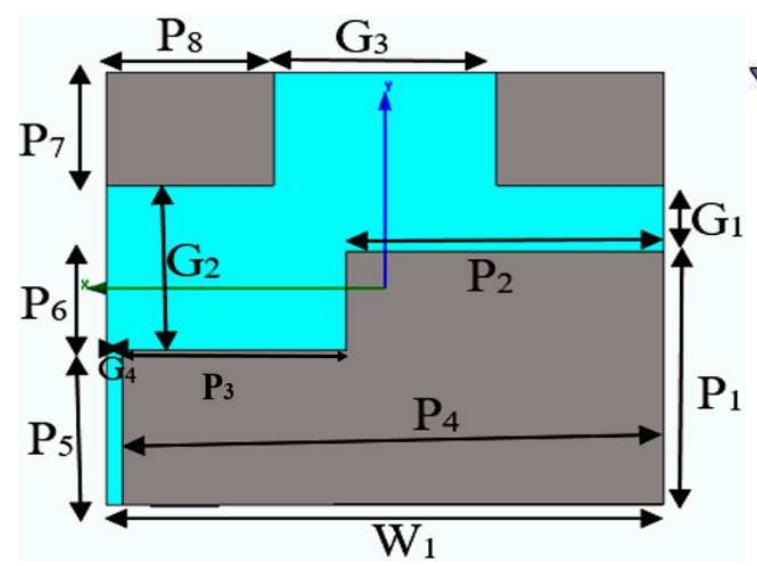

(c)

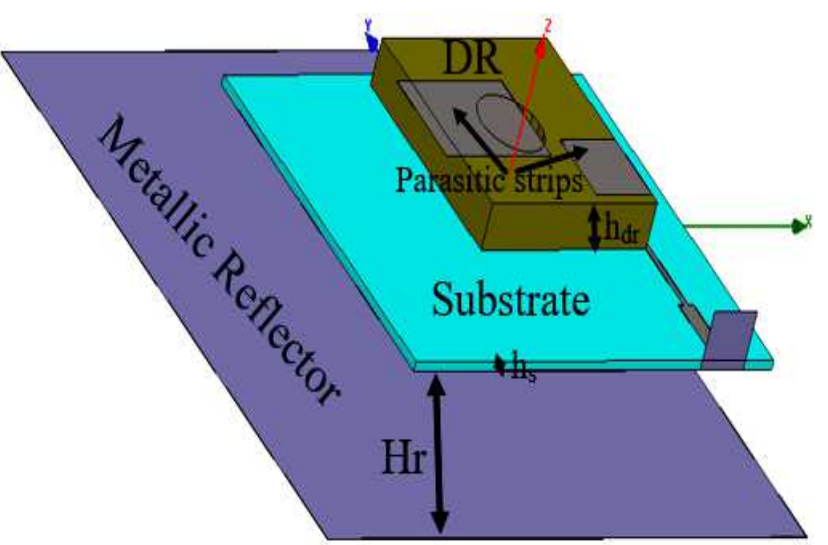

(d)

Figure 1. Configuration of proposed CPDRA: (a) Top view (b) Top view with reflector plane (c) Bottom view without reflector plane (d) Perspective view

Table 1: Proposed CPHDRA finalized parameters value

\begin{tabular}{|lcccccccc|}
\hline Parameters & $\mathrm{W}_{1}$ & $\mathrm{~W}_{2}$ & $\mathrm{~L}_{\mathrm{DR}}$ & $\mathrm{L}_{1}$ & $\mathrm{~L}_{2}$ & $\mathrm{~W}_{\mathrm{f} 1}$ & $\mathrm{~W}_{\mathrm{f} 2}$ & $\mathrm{G}_{2}$ \\
Values $(\mathrm{mm})$ & 50 & 40 & 23 & 7.7 & 14.4 & 2.2 & 0.75 & 15.3 \\
Parameters & $\mathrm{P}_{4}$ & $\mathrm{P}_{1}$ & $\mathrm{P}_{2}$ & $\mathrm{G}_{1}$ & $\mathrm{P}_{5}$ & $\mathrm{P}_{6}$ & $\mathrm{P}_{8}$ & $\mathrm{G}_{3}$ \\
Values $(\mathrm{mm})$ & 48.5 & 23.4 & 29.5 & 6.1 & 14.2 & 9.2 & 15 & 20 \\
Parameters & $\mathrm{P}_{\mathrm{s} 1}$ & $\mathrm{P}_{\mathrm{s} 2}$ & $\mathrm{P}_{\mathrm{s} 3}$ & $\mathrm{P}_{\mathrm{s} 4}$ & $\mathrm{P}_{7}$ & $\mathrm{D}_{\mathrm{a}}$ & $\mathrm{h}_{\mathrm{dr}}$ & $\mathrm{G}_{4}$ \\
Values $(\mathrm{mm})$ & 15 & 8 & 10 & 7.5 & 10.5 & 4 & 4 & 1.5 \\
\hline
\end{tabular}

\subsection{Steps performance of the Antenna}

Aimed at the understanding of the DRA steps performance, the final antenna achieved by the step results of S11, gain and AR bandwidth for UWB applications. The first antenna structure (without DR) is not reported $10 \mathrm{~dB}$ impedance bandwidth, 3dB AR bandwidth and lower gain. In second antenna structure (with DR) has reported 3.2 to $10 \mathrm{GHz}$ with $5.9 \mathrm{~dB}$ peak gain and 3-AR bandwidth is $3.55 \%$ ( 8.3 to $8.6 \mathrm{GHz}$ ). In the third antenna structure (Hollow DR) has reported 3.2 to $10.1 \mathrm{GHz}$ with $6.56 \mathrm{~dB}$ peak gain, improved impedance matching, and 3-AR bandwidth is $2.45 \%$ ( 8.86 to $9.08 \mathrm{GHz}$ ). The fourth antenna structure (With MRPS) has achieved 2.74 to $10.4 \mathrm{GHz}$ by using two MRPS on top of DR layer, resultant to give 3dB-AR bandwidth $23.8 \%$ over X-band. Final antenna have a reflector below the ground plane with distance $13.1 \mathrm{~mm}$, the antenna gain is enhanced with peak gain of $9.8 \mathrm{dBi}$, without any effect in S11 and AR bandwidth but some variations are reported in the resonance by using of a reflector. 


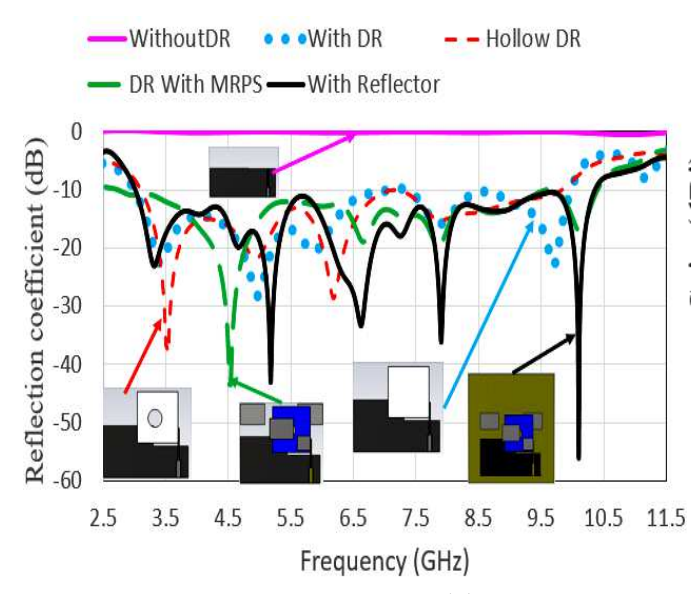

(a)

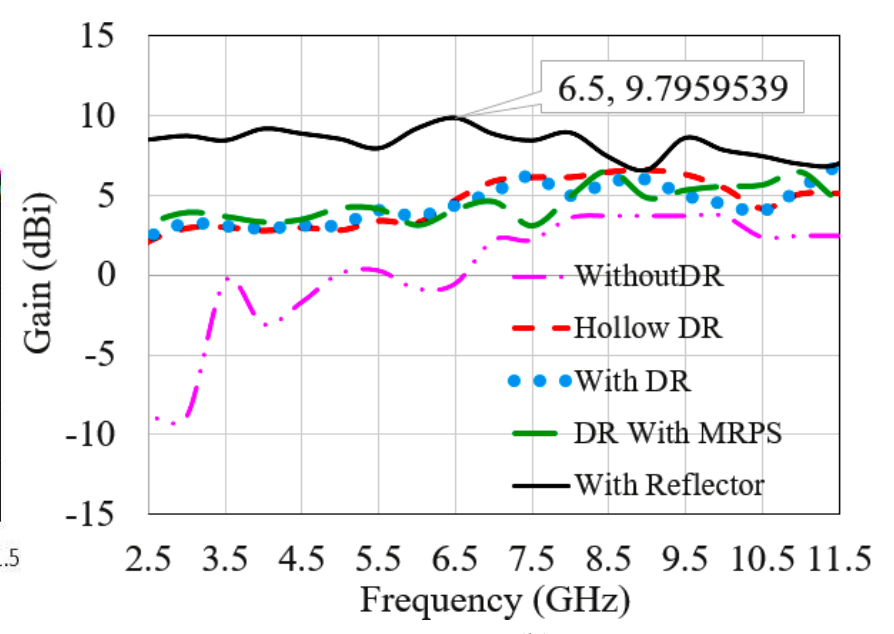

(b)

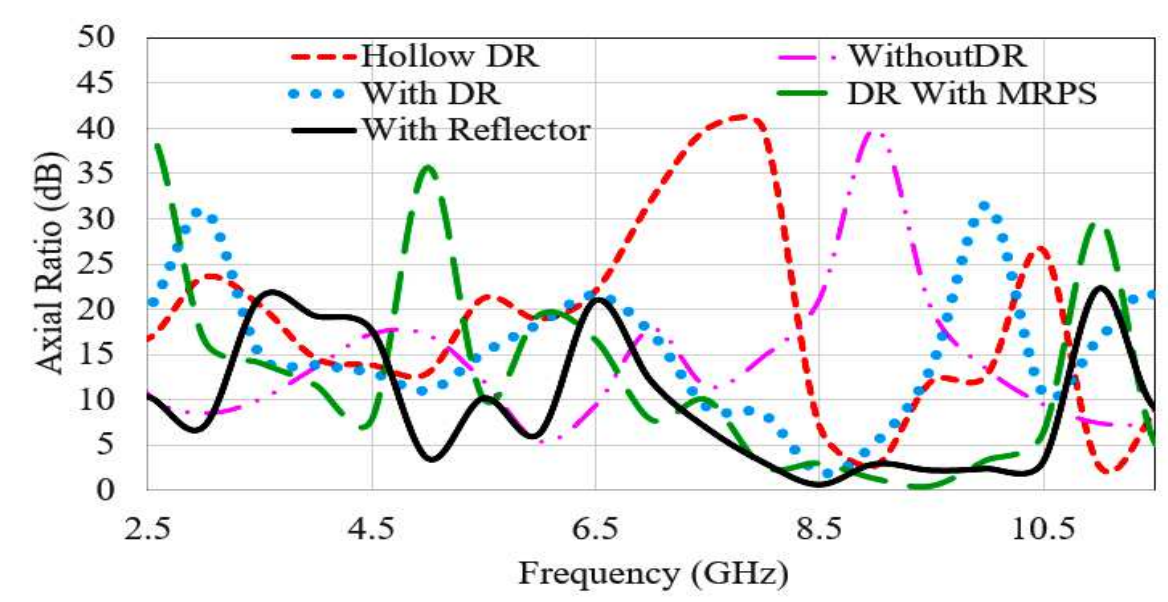

(c)

Figure 2: With metallic reflector Antenna evolution concerning frequency (a) Reflection coefficient (b) Gain (c) Axial ratio

\subsection{Perturbation Theory}

The design evolution of proposed DRA includes four steps: DR as is taken and is calculated the air-spaced volume Vs $=201.062 \mathrm{~mm}^{3}$ total volume (Vtotal) of DR is $2116 \mathrm{~mm}^{3} \mathrm{DR}$ volume $\left(\right.$ Vdra $=$ Vtotal-Vs $\left.=2116-201.062=1914.938 \mathrm{~mm}^{3}\right)$. The effective permittivity ( $\left.\varepsilon_{\text {DReff }}\right)$ of the DR depends on the volume $\left(\mathrm{V}_{\mathrm{s}}, \mathrm{Vdra}\right)$ and $\varepsilon_{\mathrm{DR}}$. With and without perturbation DR is shown in Figure 2a. So calculated $\varepsilon_{\text {DReff }}=9.05$ from (1) and quality factor Q is 1.79 (2) [28]. Thus, as the $\varepsilon_{\text {DReff }}$ and Q of DR decreases vice versa bandwidth is improved slightly, shown in Figure 2a and Figure 5b. Here, gain enhanced by the proposed perturbed geometry is shown in Figure 2c.

$$
\begin{aligned}
& \varepsilon_{\text {DReff }}=\frac{\varepsilon_{d r} \mathrm{Vdra}+\varepsilon_{0} \mathrm{Vs}}{\mathrm{Vdra}+\mathrm{Vs}} \\
& \mathrm{Q}=\frac{1+3\left(\frac{\pi}{\sqrt{9.05}}\right)^{2}}{\left(\frac{\pi}{\sqrt{9.05}}\right)^{3}\left[1+\left(\frac{\pi}{\sqrt{9.05}}\right)^{2}\right]}
\end{aligned}
$$

\subsection{FIELD MODES}

The proposed CPHDRA E-field distribution inside the DR is selected $[3,25,26]$ at $4.8,6,8.8$, and $9.9 \mathrm{GHz}$ according to the peak impedance of real part and zero for imaginary impedance, 
As per Figure $3 \mathrm{a}$ shows the fundamental mode $\mathrm{HE}_{111}$ at $4.8 \mathrm{GHz}$ and also work as a dominant mode. Figure $3 \mathrm{~b}$ is a combination of second-order mode $\mathrm{HE}_{121}$ generated at $6 \mathrm{GHz}$. Finally, $\mathrm{CP}$ radiation is achieved in the upper UWB ( 7.9 to $9.9 \mathrm{GHz}$ ),

$$
\begin{gathered}
\mathrm{f}_{\mathrm{HE}_{\mathrm{lmm}}}=\frac{\mathrm{v}}{2 \pi \sqrt{\varepsilon_{\text {DReff }}}} \sqrt{\mathrm{k}_{\mathrm{x}}^{2}+\mathrm{k}_{\mathrm{y}}^{2}+\mathrm{k}_{\mathrm{z}}^{2}} \\
\mathrm{k}_{\mathrm{x}}=\frac{1 \pi}{L_{D R}}, \mathrm{k}_{\mathrm{y}}=\frac{\mathrm{n} \pi}{L_{D R}}, \mathrm{k}_{\mathrm{z}} \tan \left(\mathrm{k}_{\mathrm{z}} \frac{\mathrm{h}_{\text {eff }}}{2}\right)=\sqrt{\left(\varepsilon_{\text {eff }}-1\right) \mathrm{k}_{0}^{2}-\mathrm{k}_{\mathrm{z}}^{2}}
\end{gathered}
$$

instead of higher-order orthogonal modes [27] generated at 8.8 and $9.9 \mathrm{GHz}$, it is shown in Figure 3 (c and d). This CPHDRA generates CP by using four metallic strips, two on the DR surface, and two are etched in the bottom of the substrate and also enhancement of the impedance bandwidth in UWB (2.74 to $10.4 \mathrm{GHz}$ ) region. Orthogonal modes generated at 8.8 and $9.9 \mathrm{GHz}, \mathrm{E}_{\mathrm{x}}$ and $\mathrm{E}_{\mathrm{y}}$ are having equal magnitude. DR is mentioned unity aspect ratio but its orthogonal resonant frequency is different because the perturbation theory in DR and metallic strips are changed ineffective dimension and permittivity of DR.

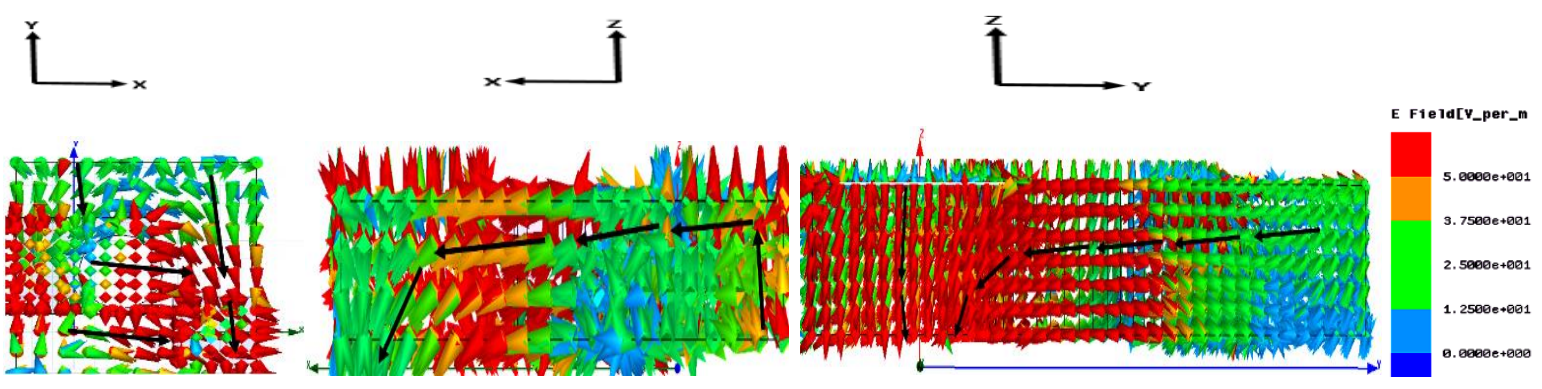

(a)
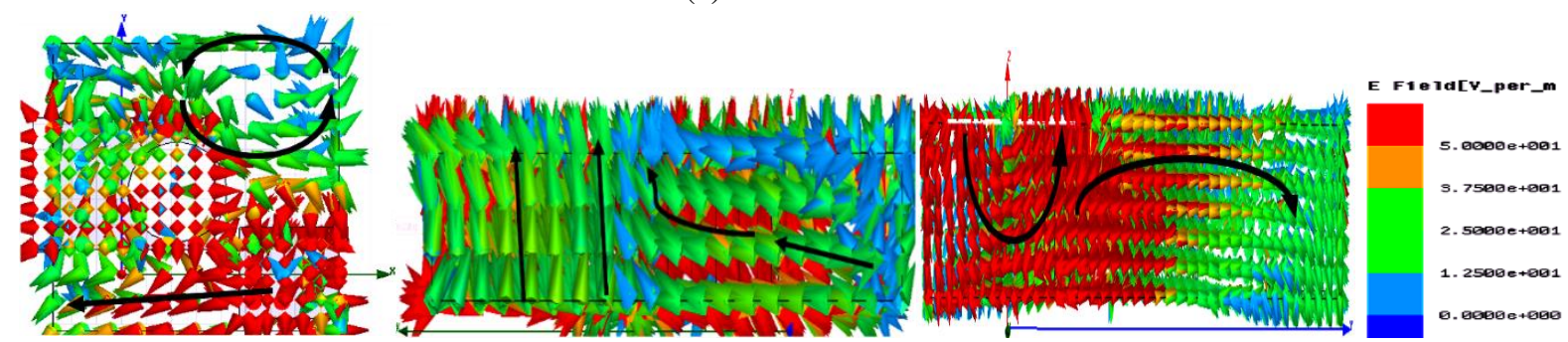

(b)

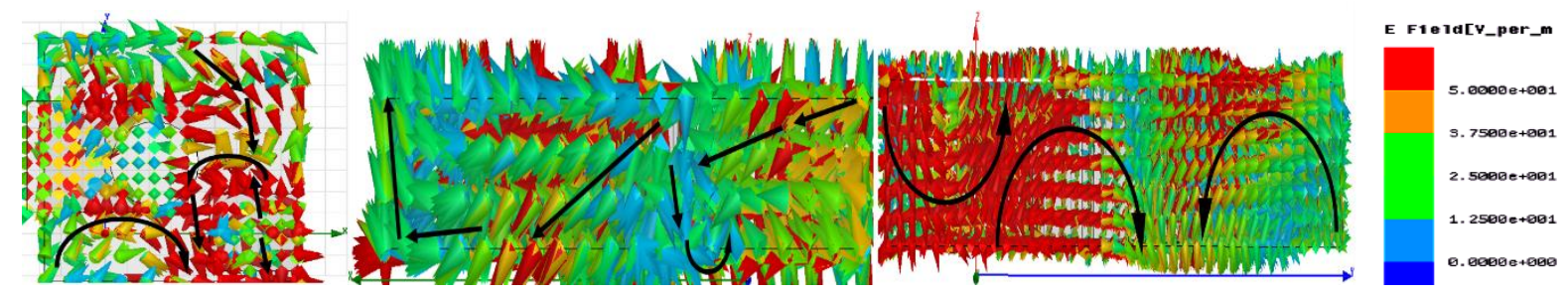

(c)
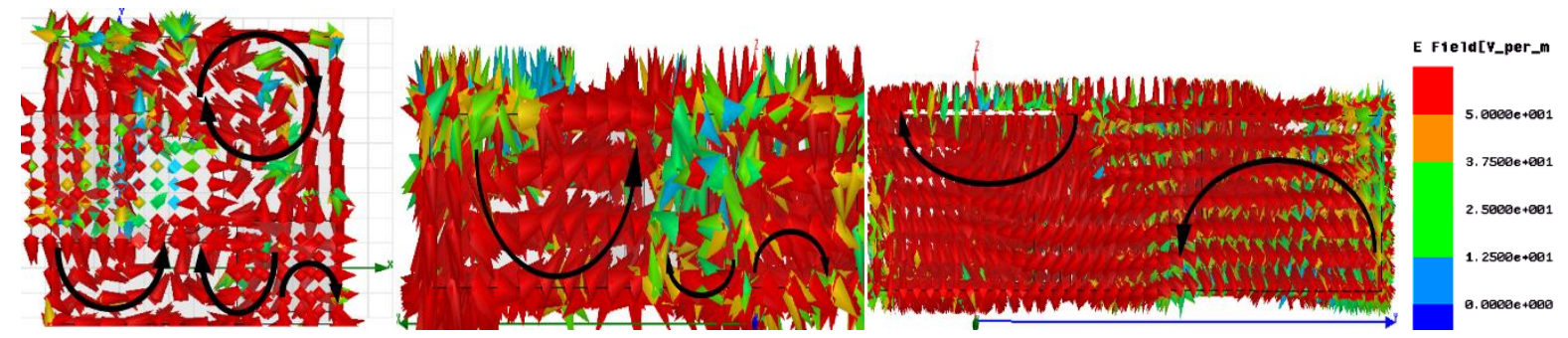
(d)

Figure 3: Near field distribution on hollow shaped DR XY, $\mathrm{XZ}$ and $\mathrm{YZ}$ plane (a) $\mathrm{HE}_{11 \delta}$ at $4.8 \mathrm{GHz}$ (b) $\mathrm{HE}_{12 \delta}$ at 6 $\mathrm{GHz}$ (c) $\mathrm{HE}_{23 \delta}$ at $8.8 \mathrm{GHz}$ (d) $\mathrm{HE}_{32 \delta}$ at $9.9 \mathrm{GHz}$

The CP mechanism is shown in Figure 4. The orthogonal modes are generated by using MRPS between 7.9 to $9.9 \mathrm{GHz}$ frequency range, on the top layer of DR is generated Ex and $\mathrm{E}_{\mathrm{y}}$ components. Z-plane has constant E-field but E-field component alignment and trapping in the XY plane by using MRPS. Hence near-field vectors constant in Z-plane.

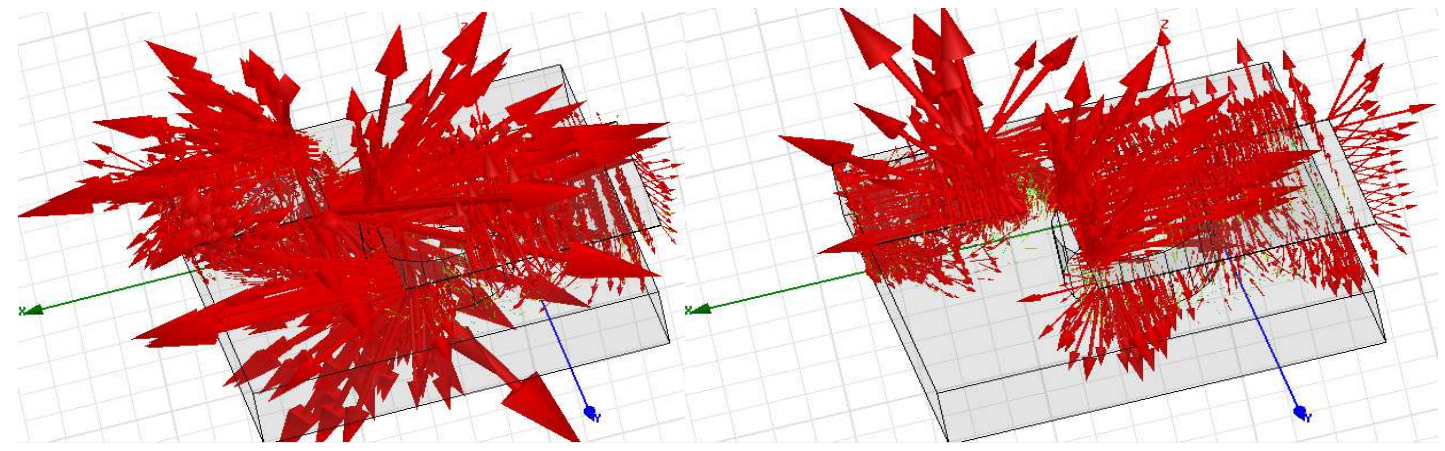

(a) 0 degree at $8.8 \mathrm{GHz}$

(b) 90 degree at $8.8 \mathrm{GHz}$

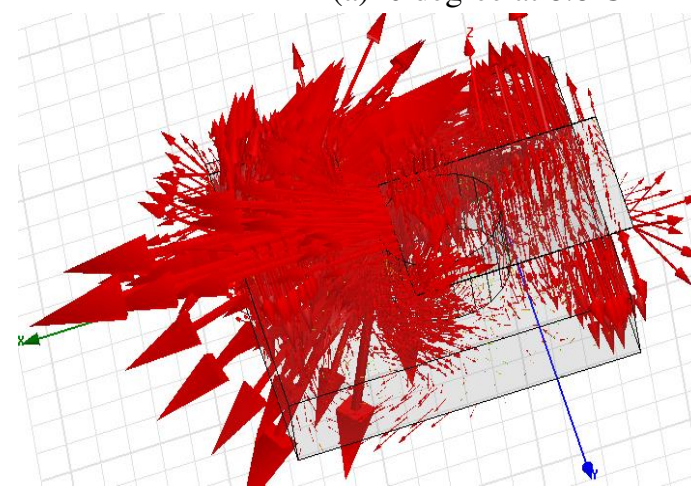

(c) 0 degree at $9.9 \mathrm{GHz}$

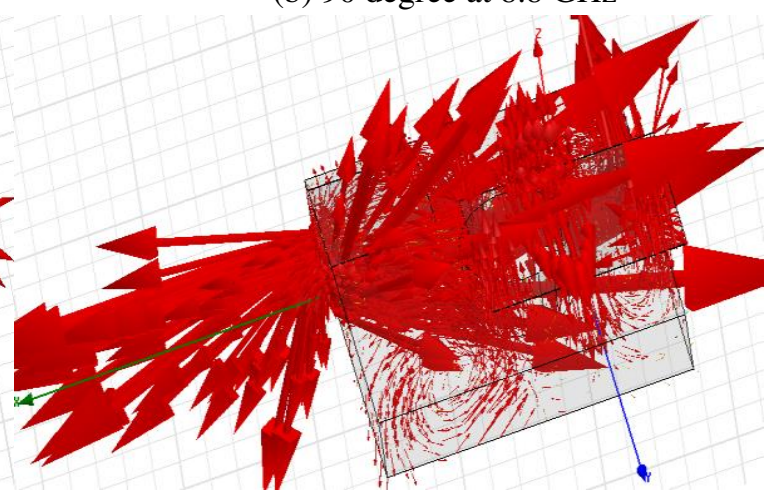

(d) 90 degree at $9.9 \mathrm{GHz}$

Figure 4: Generation of near electric field $\mathrm{E}_{\mathrm{x}}$ and $\mathrm{E}_{\mathrm{y}}$ components by using the metallic strip on top of the DR layer

\subsection{Parametric Analysis}

The proposed CPHDRA has been performed by using CST MWS 2016. For the optimization parameters of the antenna is achieved the best values by the parametric sweep. The CPHDRA by increasing of airspace changes its radius (Da) that is enhanced the

peak gain (6. 55dB) at $\mathrm{Da}=4 \mathrm{~mm}$, depicted in Figure $5 \mathrm{a}$ and 10dB impedance bandwidth (2.79 to $10.4 \mathrm{GHz})$ is shown in Figure $5 \mathrm{~b}$.

The AR bandwidth of DR is achieved by using two MRPS on top of the DR surface and two are used in the bottom layer of the substrate. These MRPS are mentioned the impedance bandwidth for UWB and achieve the 3-dB AR bandwidth. One parameter of the second MRS width varies, $S_{11}$ is depicted in Figure $6 \mathrm{a}$ and $\mathrm{AR}$ is in Figure $6 \mathrm{~b}$. Best value is reported Ws $2=$ $7.5 \mathrm{~mm}(-3.5$ to 4$)$. 


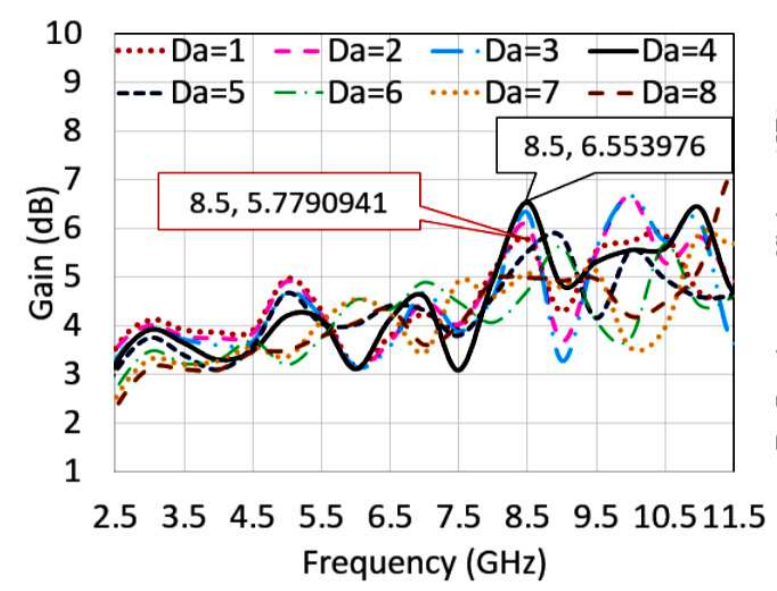

(a)

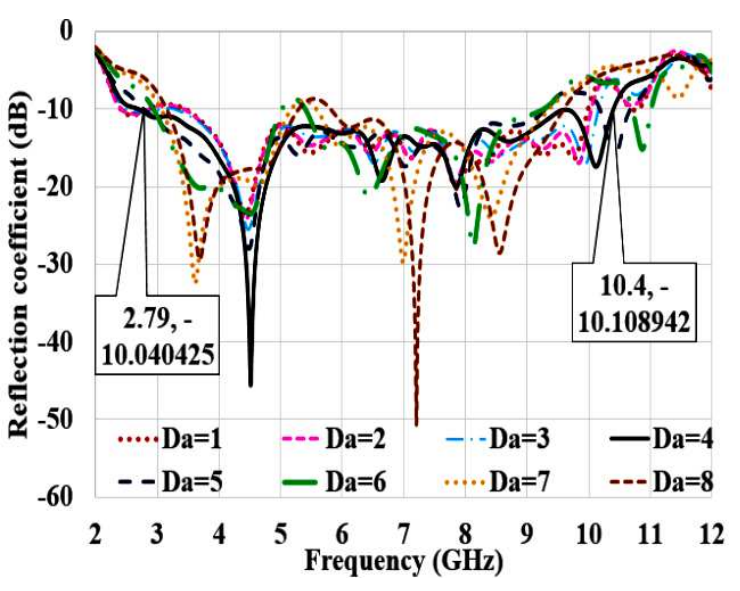

(b)

Figure 5: CPHDRA without reflector (a) Gain (b) $S_{11}$

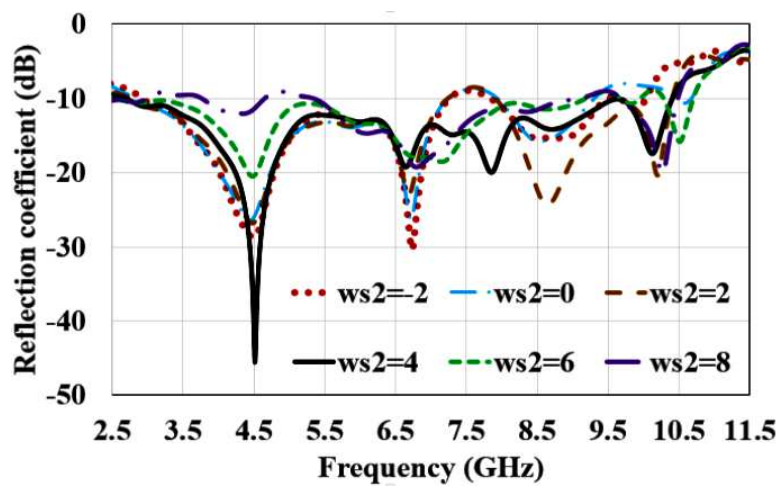

(a)

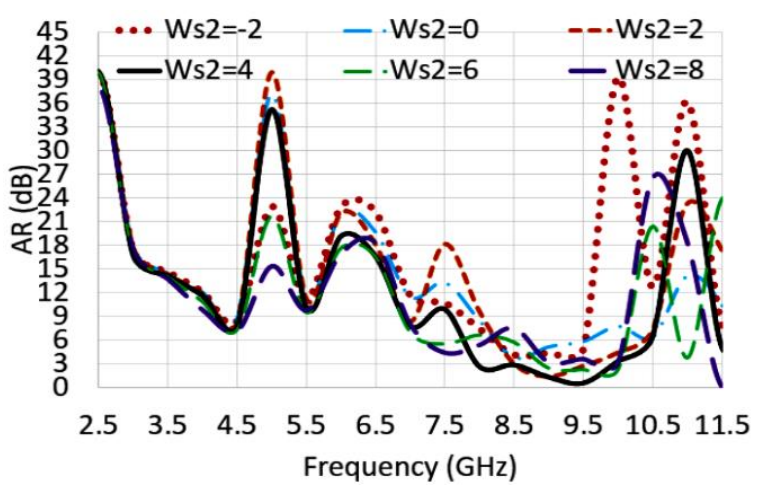

(b)

Figure 6: CPHDRA without reflector (a) $\mathrm{S}_{11}$ (b) 3-dB axial ratio bandwidth (7.9 to $9.94 \mathrm{GHz}$ )

\section{Experimental and simulated results and discussions}

The proposed antenna was fabricated using two dielectric materials: one for substrate a Rogers $5880\left(\varepsilon_{\mathrm{S}}=2.2 \& \mathrm{~h}_{\mathrm{s}}=0.8 \mathrm{~mm}\right)$ and second for DR (Alumina $\left(\varepsilon_{\mathrm{DR}}=9.8\right.$ and $\left.\mathrm{h}_{\mathrm{DR}}=4 \mathrm{~mm}\right)$ ). The proposed DR structure has a total volume of $2116 \mathrm{~mm}^{3}$ simulated and fabricated. Defected ground structure with two metallic strips is deposited on the bottom of the substrate. Air cylinder-shaped DR was extracted from an RDR and fixed over the Rogers substrate on the same side of the feedline. By using an instant Quick Fix glue is used for joining layers of DR and substrate. The snapshot of CPDRA is shown in Figure 7 (a - b), VNA E 5093A for validation of its ' $S$ ' parameter results and far-field results are measured in an anechoic chamber. The simulation part of the antenna is performed on CST MWS '16' software. 


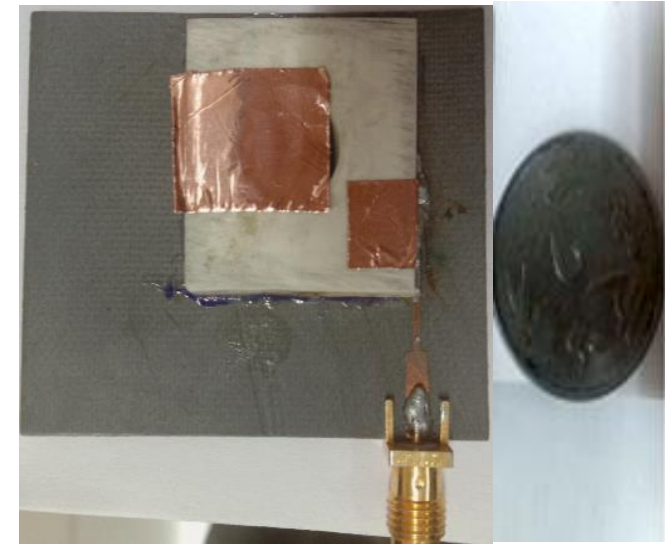

(a)

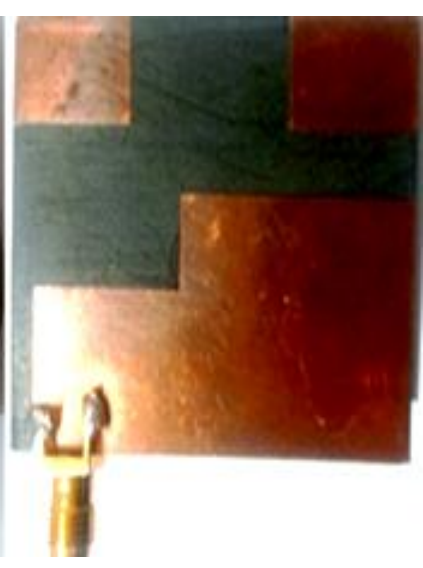

(b)

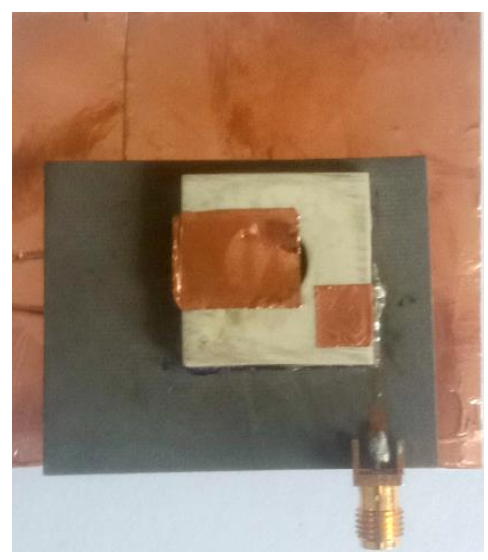

Figure 7: Snapshot of fabricated CPHDRA (a) Front view with MRPS (b) Back view (c) Front view with metallic reflector

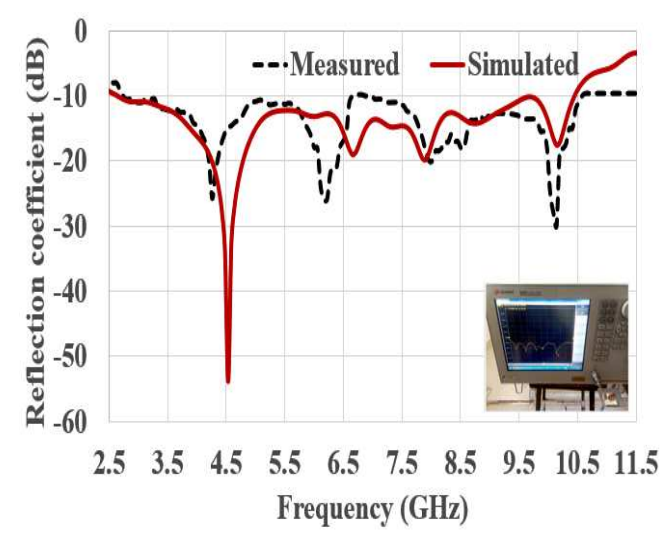

(a)

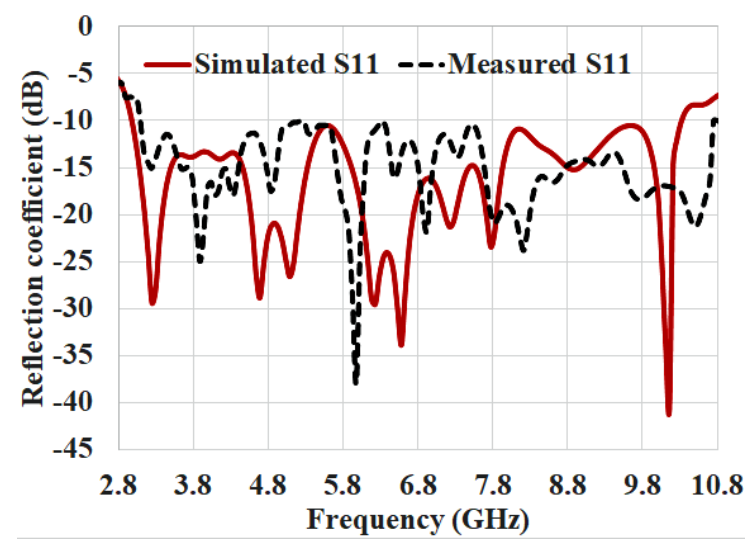

(b)

Figure 8: Simulated and measured S-parameter of proposed CPHDRA a. S11 without reflector b. S11 with reflector

Figure $8(\mathrm{a}-\mathrm{b})$ is shown the ' $\mathrm{S}$ ' parameters of the proposed CPHDRA and compared with the simulated and measured result without and with the use of a metallic reflector. It can be seen that the measured results closely follow the simulated ones. The antenna shows a measured impedance bandwidth from 2.9 to $10.49 \mathrm{GHz}$ with $119.12 \%$ bandwidths according to the center frequency of $6.42 \mathrm{GHz}$. The slight variation is reported between simulated and measured results, because of following reasons: glue, VNA cables and fabrication error.

The far-field results of CPHDRA are measured in the anechoic chamber at IIT Roorkee, India. Figure 9a shows the simulated and measured AR with a good agreement between them. The antenna provides 3-dB AR bandwidth in the bore-sight direction $(\varphi=0$ and $\varphi=90)$. The measured impedance bandwidth is slightly wider than the simulated ones and AR bandwidth slightly shifted due to the fabrication error (quick fix glue for joining of DR and Substrate layer) and measurement setup (cable loss). Figure $9 \mathrm{~b}$ shows the simulated and measured gain of the antenna. Without the metallic reflector, the peak gain of an antenna is reported to be $6.55 \mathrm{~dB}$ in approximately bore-sight direction and when the antenna is introduced a metallic reflector, gain enhanced $9.8 \mathrm{dBi}$. Also, Figure $9 \mathrm{~b}$ shows the simulated radiation efficiency. The maximum and average radiation efficiency is $97.2 \%$ and $92.57 \%$ respectively. 


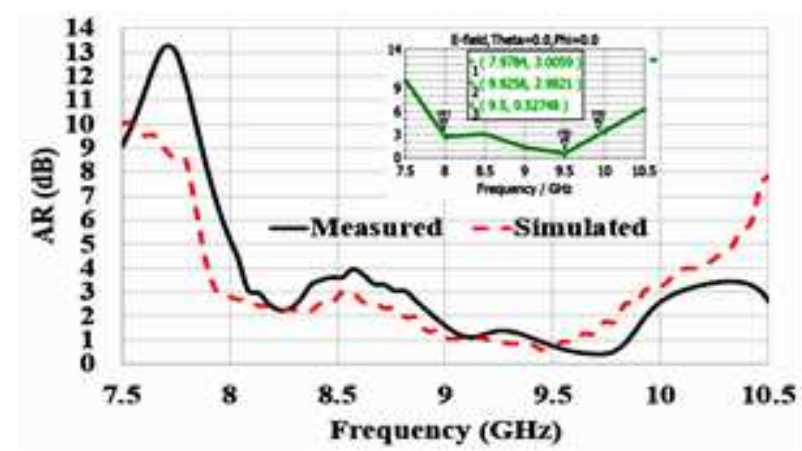

(a)

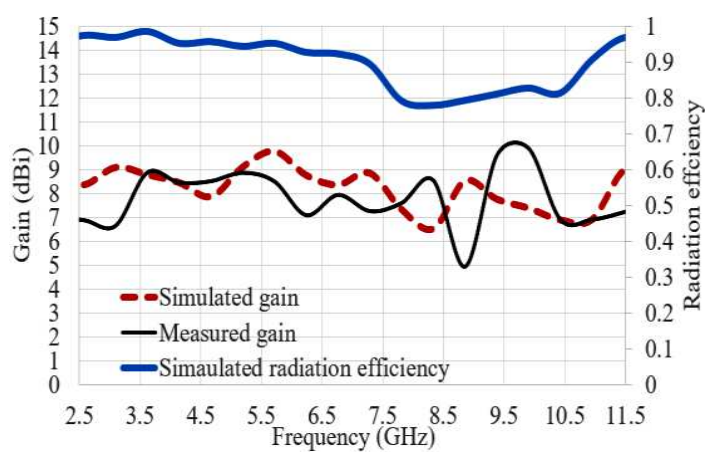

(b)

Figure 9: proposed CPHDRA a. axial ratio plot, b. Gain and simulated radiation efficiency

Figure 10 and Figure 11 show the radiation pattern at 8.8 and $9.9 \mathrm{GHz}$ with azimuthal and elevation angle. The effect of MRPS in antenna provides the dominant LHCP field over the RHCP field ( $>18 \mathrm{~dB}$ ) from frequency 6.5 to $10.4 \mathrm{GHz}$. The antenna operates fundamental and higher-order modes, the maximum radiations is reported in bore-sight direction. MRPS provides the higher-order orthogonal modes at 8.8 and $9.9 \mathrm{GHz}$ vice versa $\mathrm{CP}$ is generated in X-band.

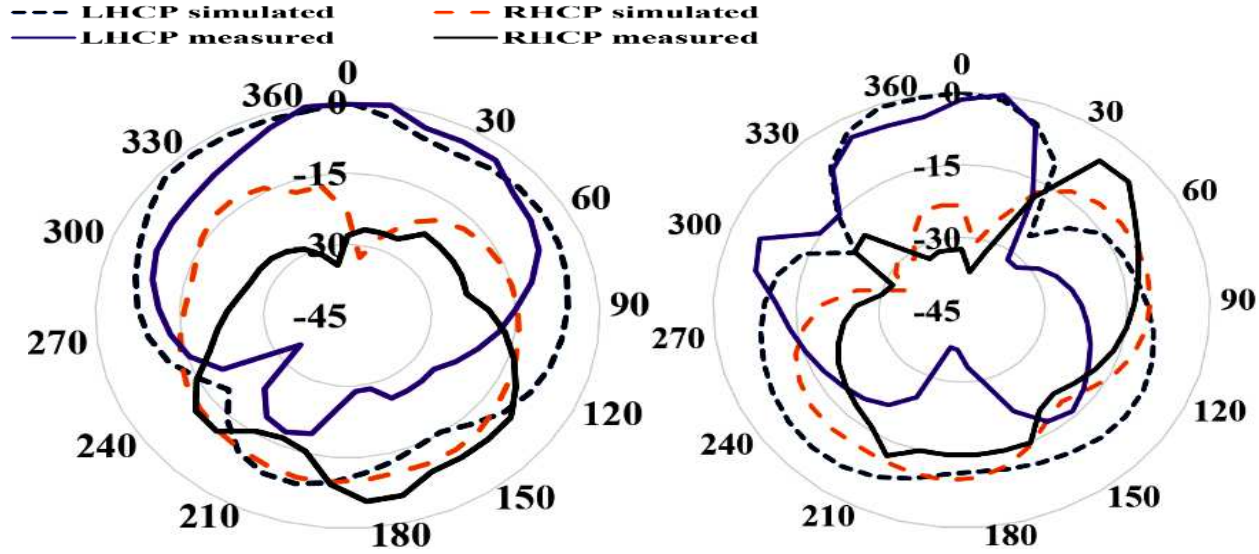

(a) $\mathrm{Phi}=0$

(b) $\mathrm{Phi}=90$

Figure 10: LHCP and RHCP pattern of antenna at $8.8 \mathrm{GHz}$

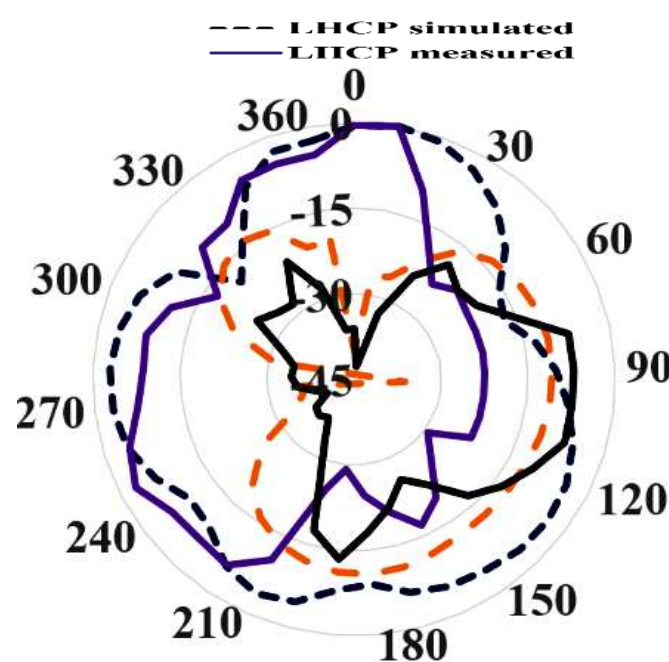

(a) $\mathrm{Phi}=0$

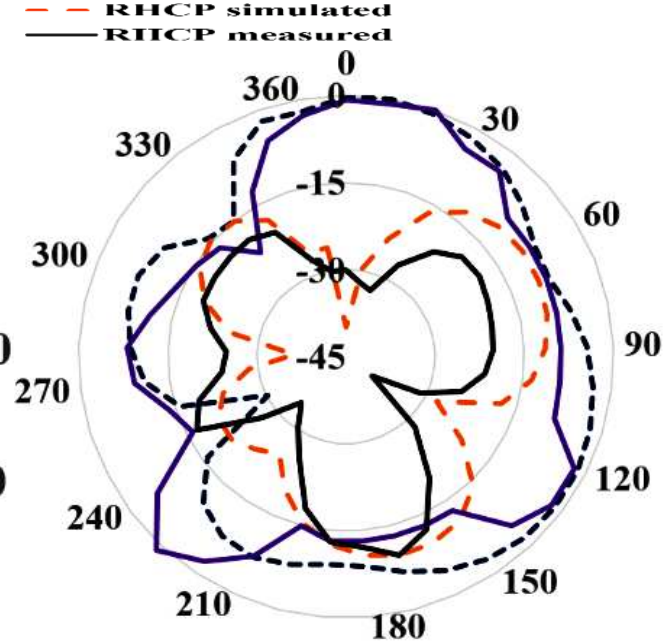

(b) $\mathrm{Phi}=90$

Figure 11: LHCP and RHCP pattern of antenna at $9.9 \mathrm{GHz}$ 


\section{Conclusion}

In this communication, a high gain CPHDRA is designed, simulated and fabricated for UWB applications. The gain of antenna is enhanced by using a metallic reflector hanged below the ground plane and hollow concept of DR. Two MRPS is used to achieve the 3-dB AR bandwidth (23.8\%). The simulated and measured impedance bandwidth is $118.46 \%$ and $121.12 \%$ with high gain in the entire UWB range. The proposed antenna obtained UWB range by the combination of near field properties first, second, and third-order hybrid modes $\mathrm{HE}_{11 \delta}, \mathrm{HE}_{21 \delta}, \mathrm{HE}_{23 \delta}$, and $\mathrm{HE}_{32 \delta}$ at 4.4, 6, 8.8, and $9.9 \mathrm{GHz}$. Two orthogonal modes $\mathrm{HE}_{23 \delta}$, and $\mathrm{HE}_{32 \delta}$ are generated at 8.8 and $9.9 \mathrm{GHz}$ that make the DRA radiate circularly polarized waves for X-band from 8 to $10.1 \mathrm{GHz}$. The peak simulated radiation efficiency is reported by $97.2 \%$. The proposed CPHDRA can be used for the satellite communication system, $\mathrm{X}$ band for defence and multimedia video applications.

\section{Disclosure statement}

No potential conflict of interest was reported by the author.

\section{References}

[1] E.T. Docket, Docket 98-153, FCC, Revision of part 15 of the commission's rules regarding ultrawideband transmission systems. Technical Report, 2002.

[2] Luk, K.M. \& Leung, K.W. (2003). Dielectric Resonator Antenna. U. K.: Research Studies Press, UK, 2003.

[3] Yaduvanshi R.S. and Parthasarathy H.: 'Rectangular dielectric resonator antennas', Berlin: Springer. 2016.

[4] Guha, D. \& Kumar, C. (2016). Microstrip Patch versus Dielectric Resonator Antenna Bearing All Commonly Used Feeds: An experimental study to choose the right element. IEEE Antennas Propag. Mag., 58(1), 45-55.

[5] Ryu, K. S. \& Kishk, A. A. (2010). Ultrawideband dielectric resonator antenna with broadside patterns mounted on a vertical ground plane Edge. IEEE Trans. Antennas Propag., 58(4), 1047-1053.

[6] Abedian, M., Rahim, S.K., Danesh, S., Hakimi, S., Cheong, L.Y. \& Jamaluddin, M.H. (2014). Novel design of compact UWB dielectric resonator antenna with dual-band-rejection characteristics for WiMAX/WLAN bands. IEEE Antennas and Wireless Propagation Letters, 14, 245-248.

[7] T. A. Denidni and Z. Weng, "Hybrid ultrawideband dielectric resonator antenna and band-notched designs," IET Microwaves, Antennas Propag., vol. 5, no. 4, pp. 450-458, 2011.

[8] A. H. Majeed, A. S. Abdullah, K. H. Sayidmarie, R. A. Abd-Alhameed, F. Elmegri, and J. M. Noras, "Balanced dual-segment cylindrical dielectric resonator antennas for ultra-wideband applications," IET Microwaves, Antennas Propag., vol. 9, no. 13, pp. 1478-1486, 2015.

[9] C Ozzaim, F Ustuner and N Tarim, "Stacked conical ring dielectric resonator antenna excited by a monopole for improved ultrawide bandwidth" IEEE Transactions on Antennas and Propagation. Vol. 61(3), pp. 1435-8, 2013.

[10] XL Liang, TA Denidni, "H-shaped dielectric resonator antenna for wideband applications," IEEE Antennas and Wireless propagation letters, vol. 7, pp. 163-6, 2008.

[11] TA Denidni, Z Weng, and M Niroo-Jazi, "Z-shaped dielectric resonator antenna for ultrawideband applications," IEEE Transactions on Antennas and Propagation, vol. 58(12), pp. 4059-62, 2010.

[12] RD Gupta and MS Parihar, "Investigation of an asymmetrical E-shaped dielectric resonator antenna with wideband characteristics," IET Microwaves, Antennas \& Propagation, vol. 10(12), pp. 1292-7, 2016.

[13] M Khalily, MK Rahim, AA Kishk, and S Danesh, "Wideband P-shaped dielectric resonator antenna," Radioengineering. Vol. 22(1), pp. 281-5, 2013.

[14] K. L. Wong, N. C. Chen, and H. T. Chen, "Analysis of a Hemispherical Dielectric Resonator Antenna with an Airgap," IEEE Microw. Guid. Wave Lett., vol. 3, no. 10, pp. 355-357, 1993. 
[15] E. H. Lim and K. W. Leung, "Novel application of the hollow dielectric resonator antenna as a packaging cover," IEEE Trans. Antennas Propag., vol. 54, no. 2, pp. 484-487, 2006.

[16] K. Lu, K. W. Leung, and Y. M. Pan, "Theory and experiment of the hollow rectangular dielectric resonator antenna," IEEE Antennas Wirel. Propag. Lett., vol. 10, no. 7002689, pp. 631-634, 2011.

[17] G. Varshney, S. Gotra, V. S. Pandey, and R. S. Yaduvanshi, "Inverted-Sigmoid Shaped Multiband Dielectric Resonator Antenna with Dual-Band Circular Polarization," IEEE Trans. Antennas Propag., vol. 66, no. 4, pp. 2067-2072, 2018.

[18] G. Varshney, V. S. Pandey, and R. S. Yaduvanshi, "Axial ratio bandwidth enhancement of a circularly polarized rectangular dielectric resonator antenna," Int. J. Microw. Wirel. Technol., vol. 10, no. 8, pp. 933-941, 2018.

[19] Y. M. Pan and K. W. Leung, "Wideband omnidirectional circularly polarized dielectric resonator antenna with parasitic strips," IEEE Trans. Antennas Propag., vol. 60, no. 6, pp. 2992-2997, 2012.

[20] S. Gotra, G. Varshney, R. S. Yaduvanshi, and V. S. Pandey, "Dual-band circular polarisation generation technique with the miniaturization of a rectangular dielectric resonator antenna," IET Microwaves, Antennas Propag., vol. 13, no. 10, pp. 1742-1748, 2019.

[21] G. Varshney, V. S. Pandey, and R. S. Yaduvanshi, "Dual-band fan-blade-shaped circularly polarised dielectric resonator antenna," IET Microwaves, Antennas Propag., vol. 11, no. 13, pp. 6-9, 2017.

[22] Lim EH, Leung KW, Fang XS.: 'The compact circularly-polarized hollow rectangular dielectric resonator antenna with an underlaid quadrature coupler', IEEE Transactions on Antennas and Propagation, 2010, 59(1), pp. 288-93.

[23] Iqbal J, Illahi U, Sulaiman MI, Alam M, Mazliham MS.: 'Circularly polarized bandwidth enhancement using hollow cylindrical DRA', International Conference on Engineering Technology and Technopreneurship (ICE2T) 2017, pp. 1-4. IEEE.

[24] Lu Kai and Leung KW.: 'Wideband circularly polarized hollow dielectric resonator antenna with a parasitic strip', InProceedings of 2011 Cross Strait Quad-Regional Radio Science and Wireless Technology Conference 2011, Vol. 1, pp. 514-5. IEEE.

[25] R. K. Gangwar, A. Sharma, M. Gupta, and S. Chaudhary, "Hybrid cylindrical dielectric resonator antenna with HE1 $1 \delta$ and HE12 $\delta$ mode excitation for wireless applications," Int. J. RF Microw. Comput. Eng., vol. 26, no. 9, pp. 812-818, 2016.

[26] A. Sharma and R. K. Gangwar, "Triple-band dual-polarized hybrid cylindrical dielectric resonator antenna with hybrid modes excitation," Prog. Electromagn. Res. C, vol. 67, pp. 97-105, 2016.

[27] R. Kumar and R. K. Chaudhary, "Investigation of higher order modes excitation through F-shaped slot in rectangular dielectric resonator antenna for wideband circular polarization with broadside radiation characteristics," Int. J. RF Microw. Comput. Eng., vol. 28, no. 6, pp. 1-11, 2018.

[28] Kumar, J., Mukherjee, B. \& Gupta, N. (2015). A novel tetraskelion dielectric resonator antenna for wideband applications. Microwave and Optical Technology Letters, 57(12), 2781-86. 


\section{Figures}

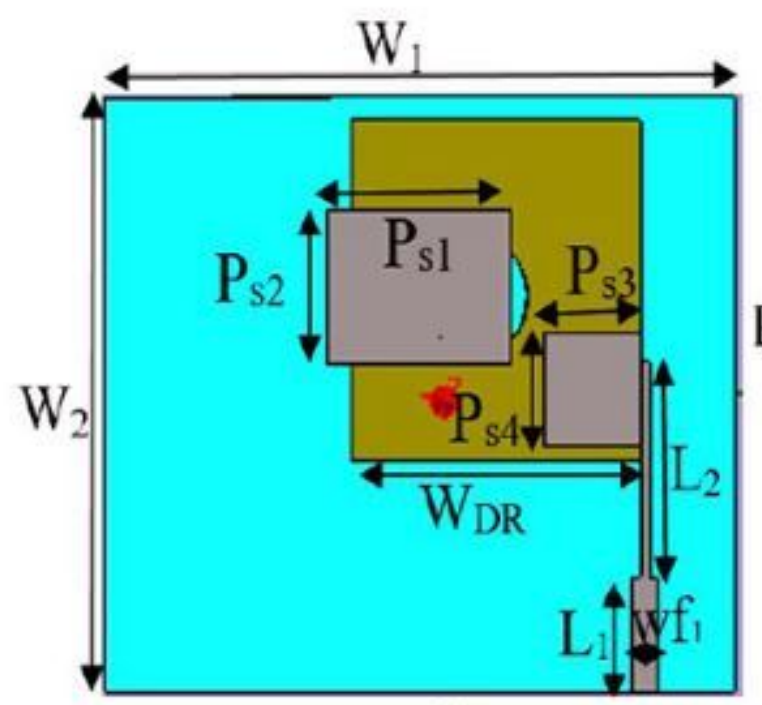

(a)

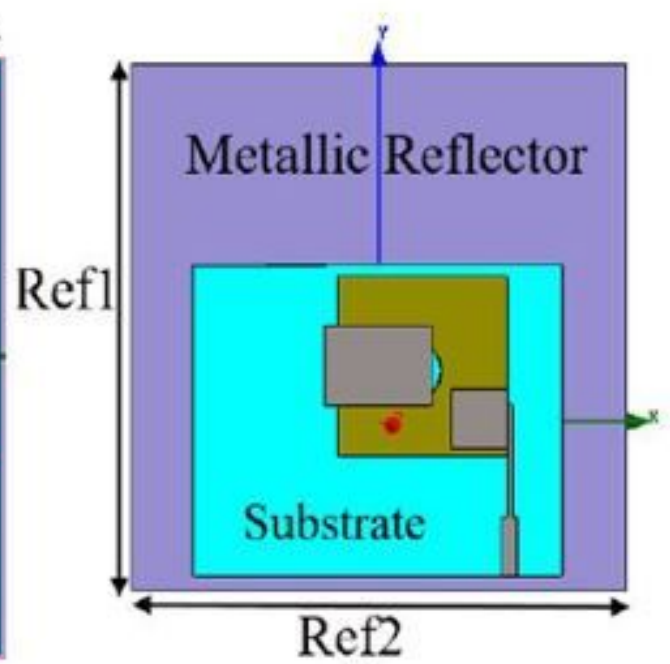

(b)

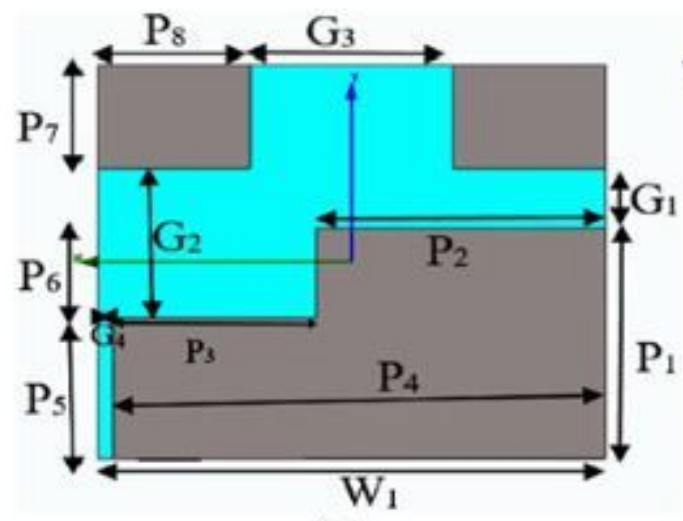

(c)

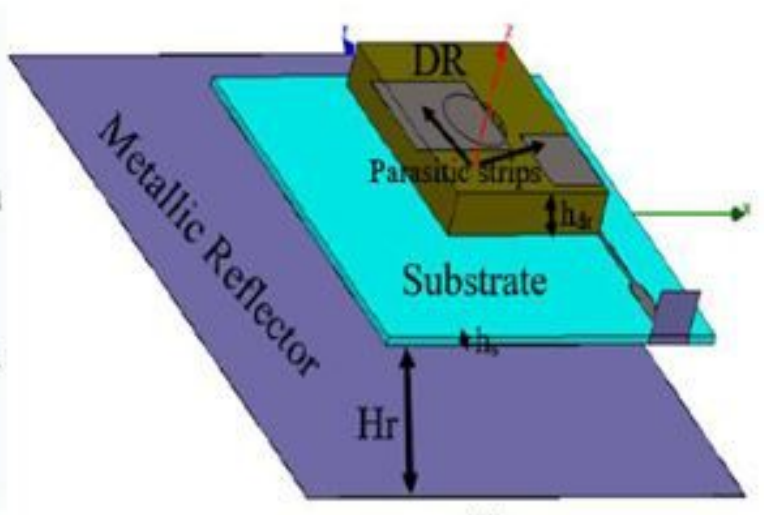

(d)

Figure 1

Configuration of proposed CPDRA: (a) Top view (b) Top view with reflector plane (c) Bottom view without reflector plane (d) Perspective view 


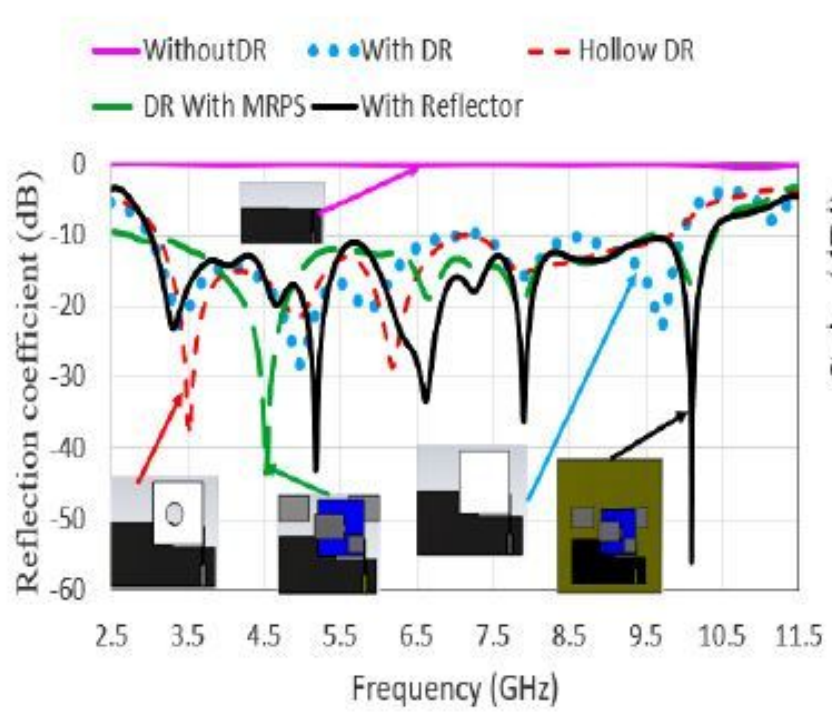

(a)

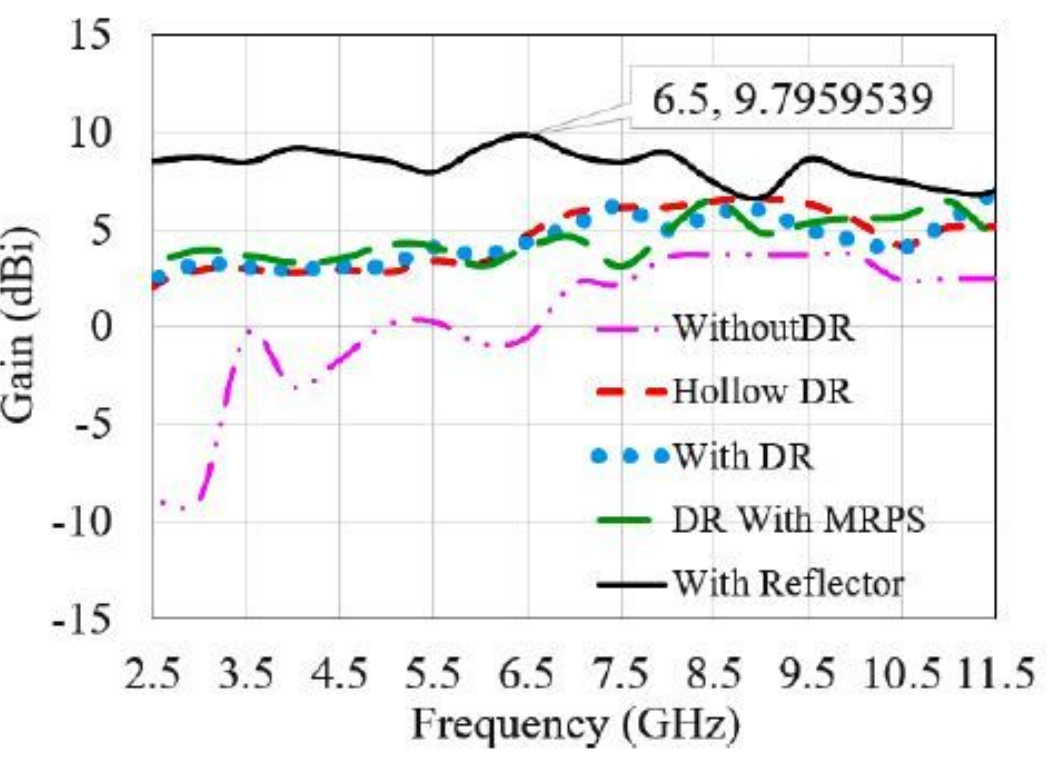

(b)

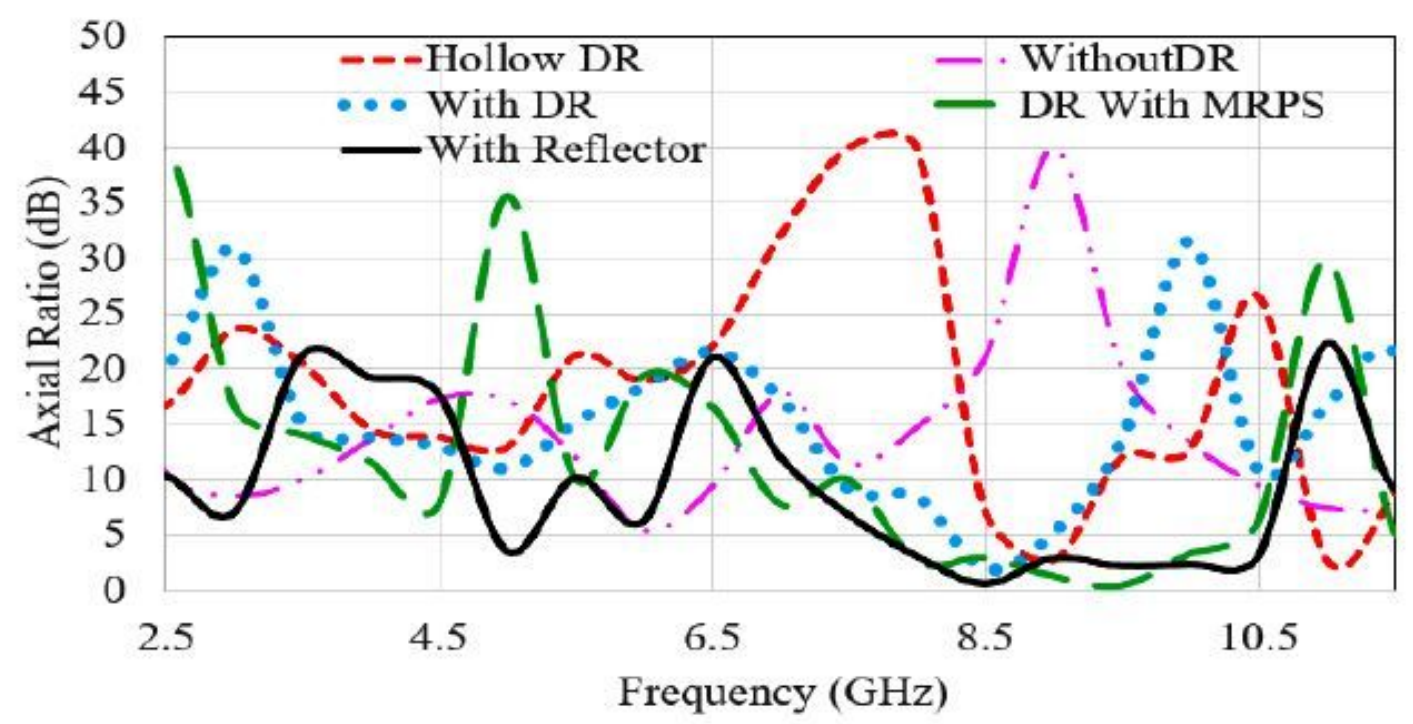

(c)

Figure 2

With metallic reflector Antenna evolution concerning frequency (a) Reflection coefficient (b) Gain (c) Axial ratio 


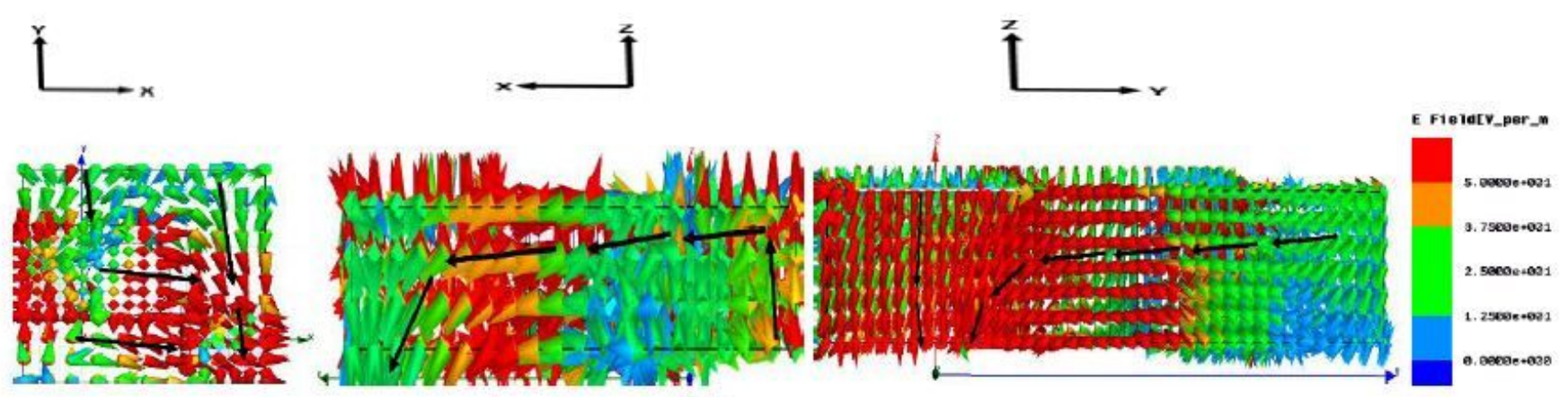

(a)
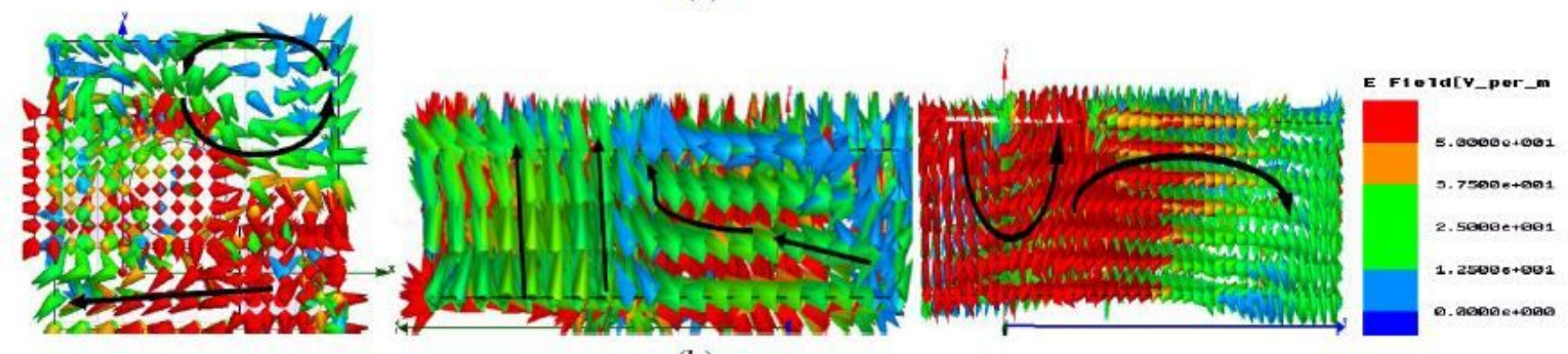

(b)
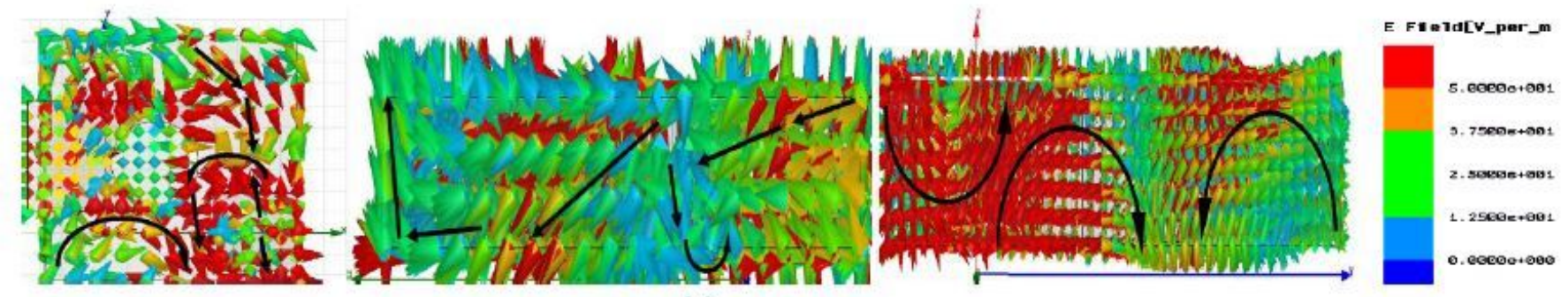

(c)

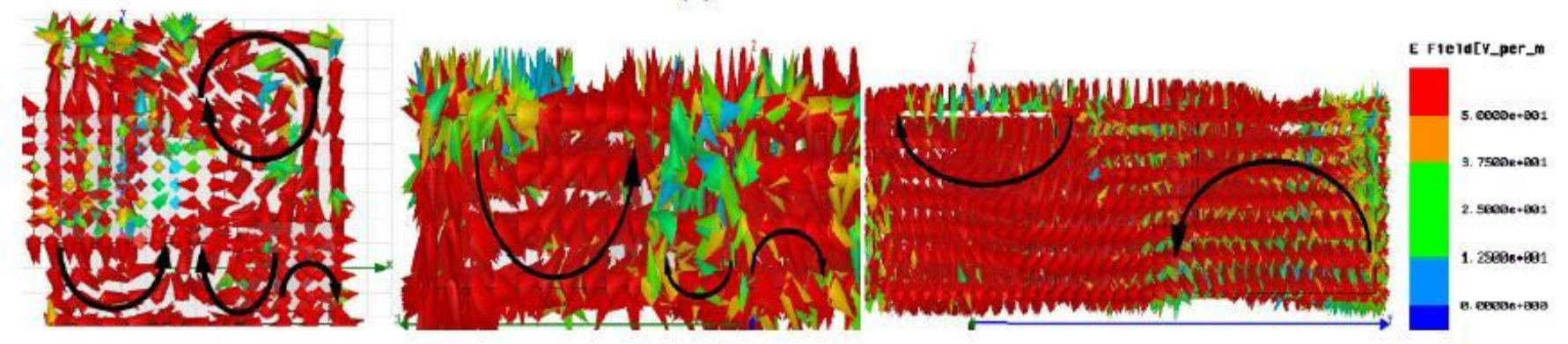

Figure 3

Near field distribution on hollow shaped DR XY, XZ and YZ plane (a) HE11 $\delta$ at $4.8 \mathrm{GHz}$ (b) HE12 $\delta$ at 6

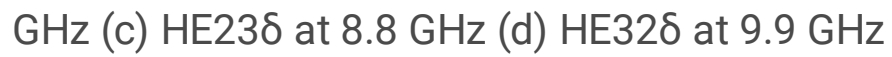




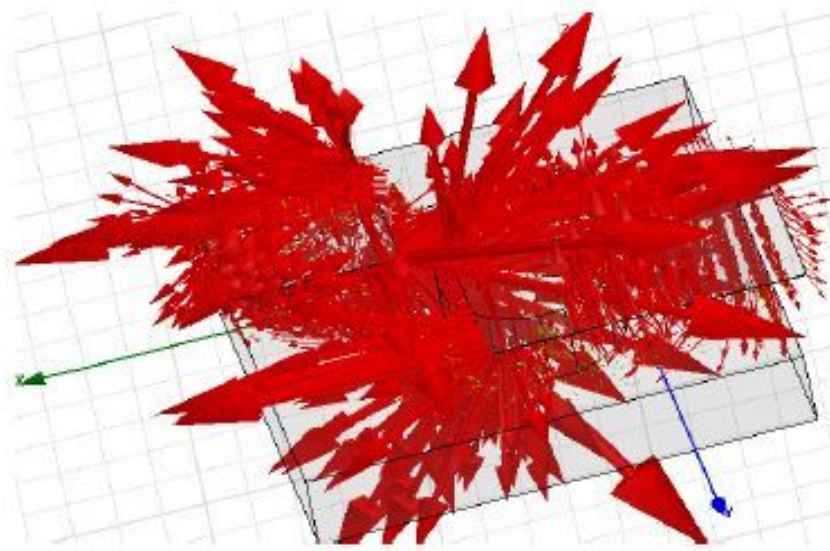

(a) 0 degree at $8.8 \mathrm{GHz}$

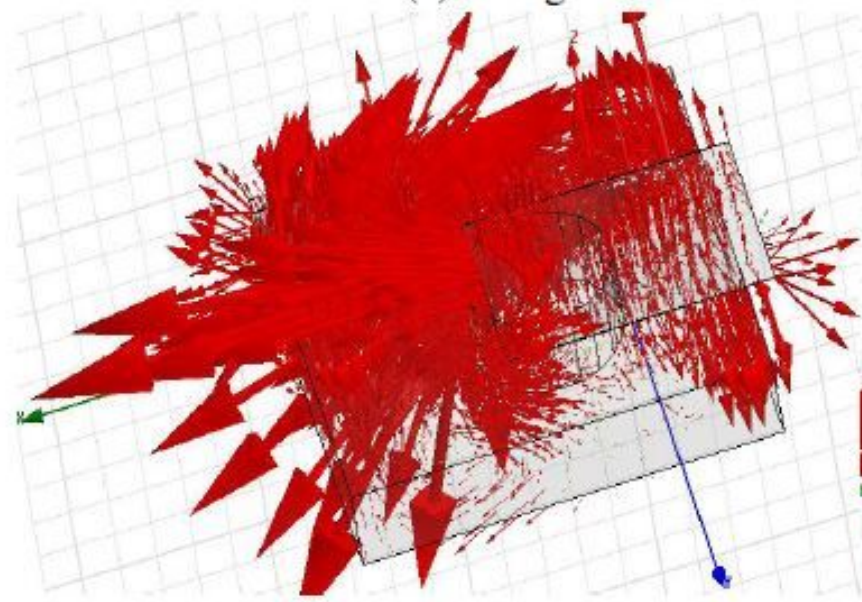

(c) 0 degree at $9.9 \mathrm{GHz}$

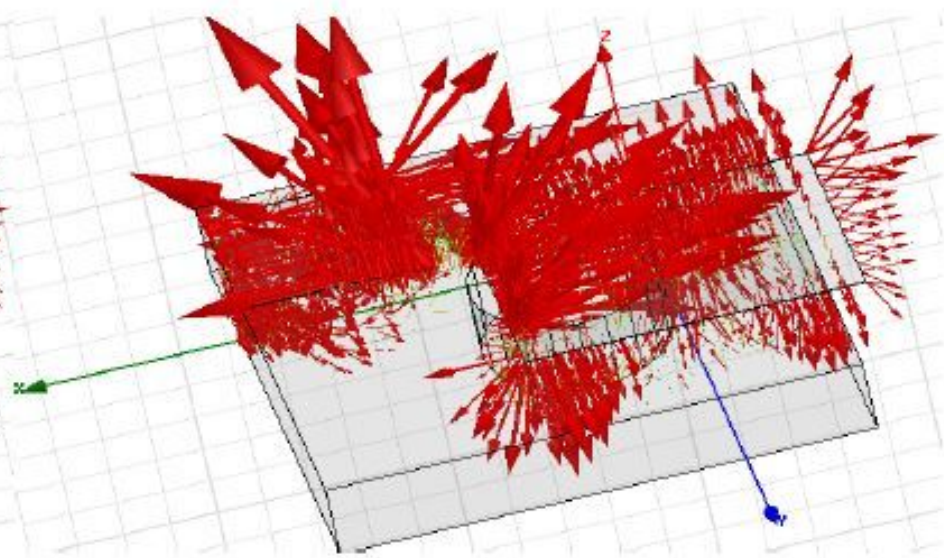

(b) 90 degree at $8.8 \mathrm{GHz}$

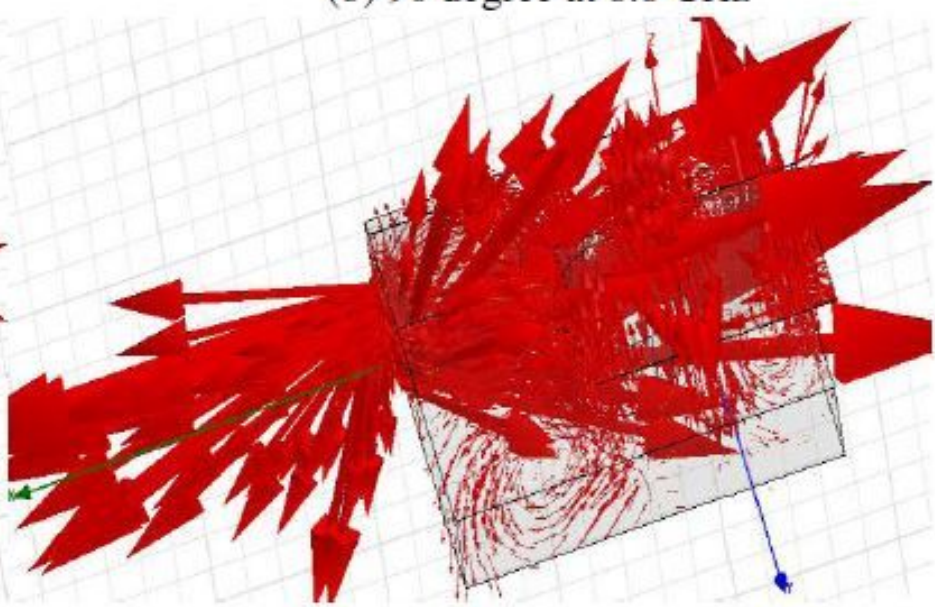

(d) 90 degree at $9.9 \mathrm{GHz}$

Figure 4

Generation of near electric field Ex and Ey components by using the metallic strip on top of the DR layer

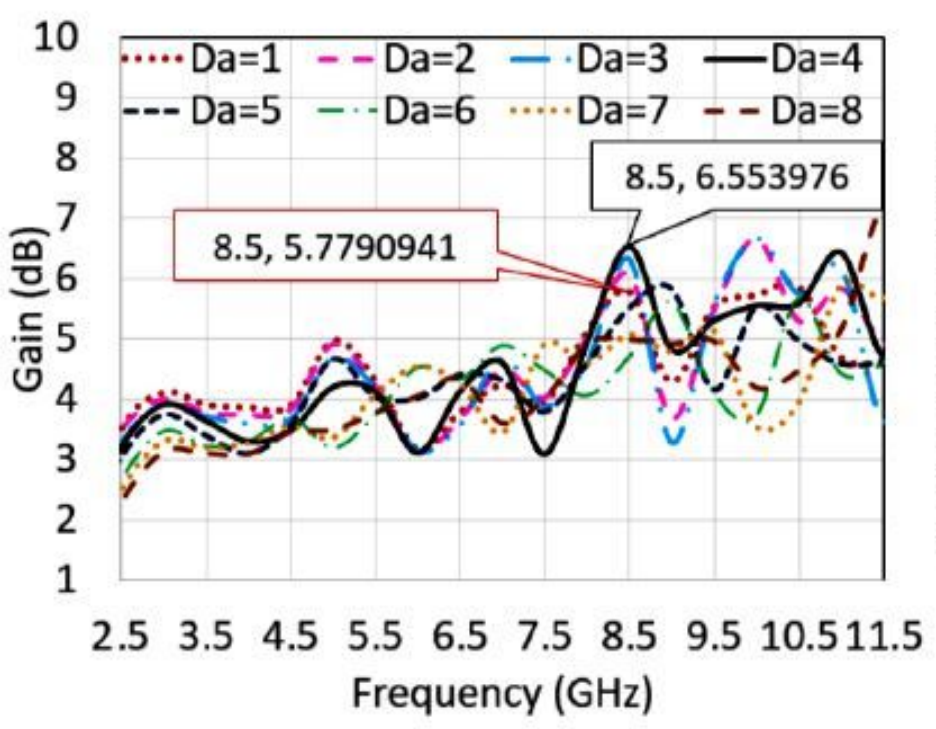

(a)

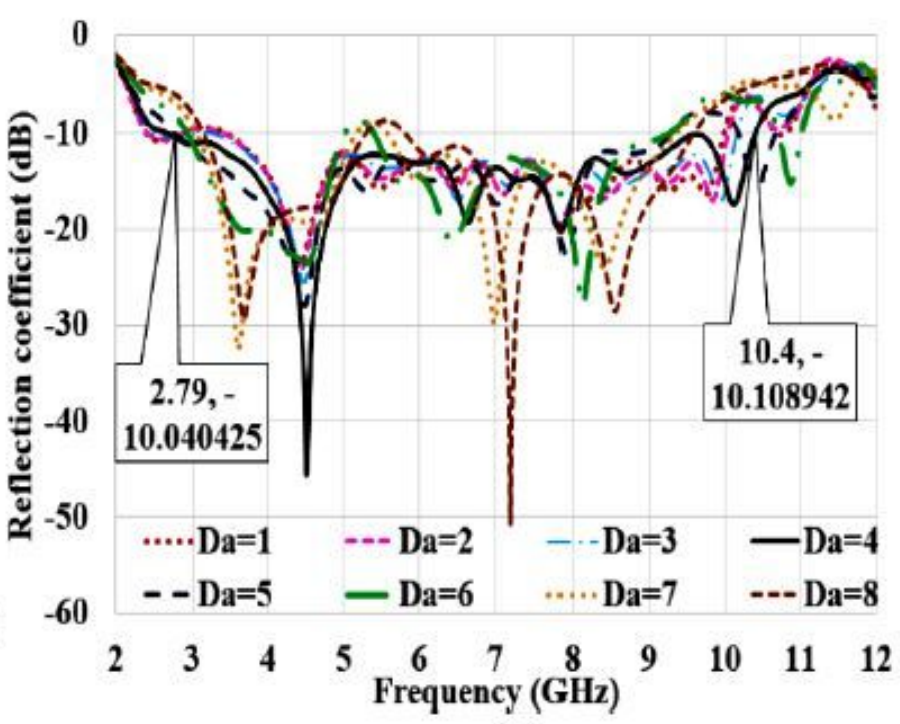

(b)

Figure 5 
CPHDRA without reflector (a) Gain (b) S11

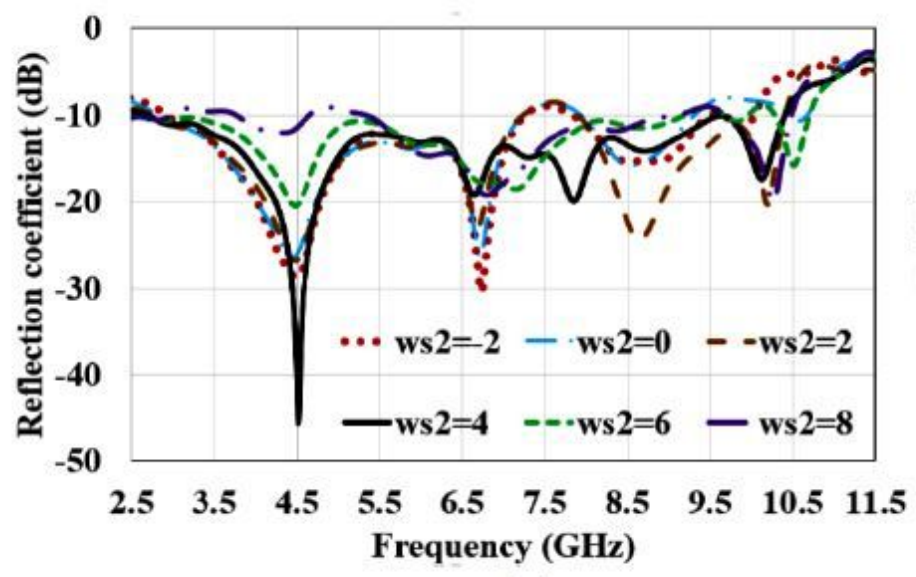

(a)

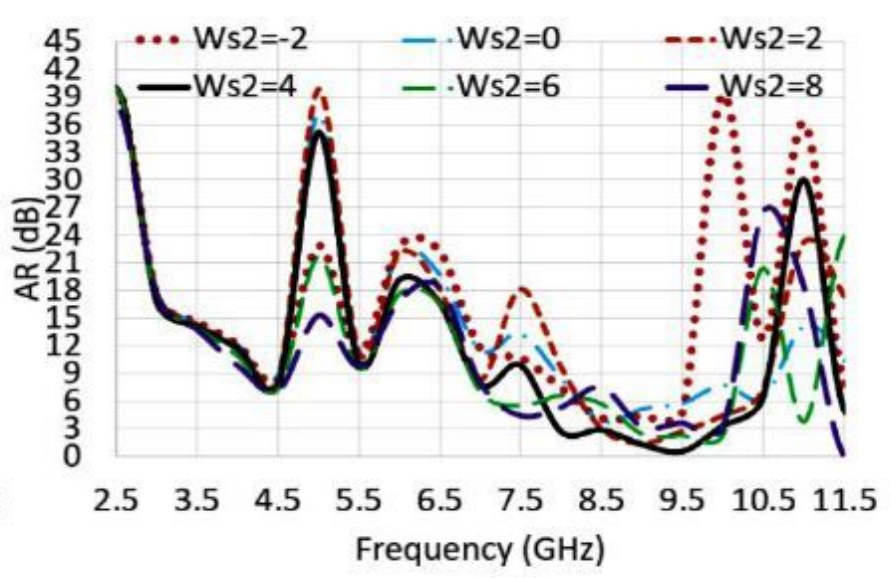

(b)

\section{Figure 6}

CPHDRA without reflector (a) S11 (b) 3-dB axial ratio bandwidth (7.9 to $9.94 \mathrm{GHz}$ )

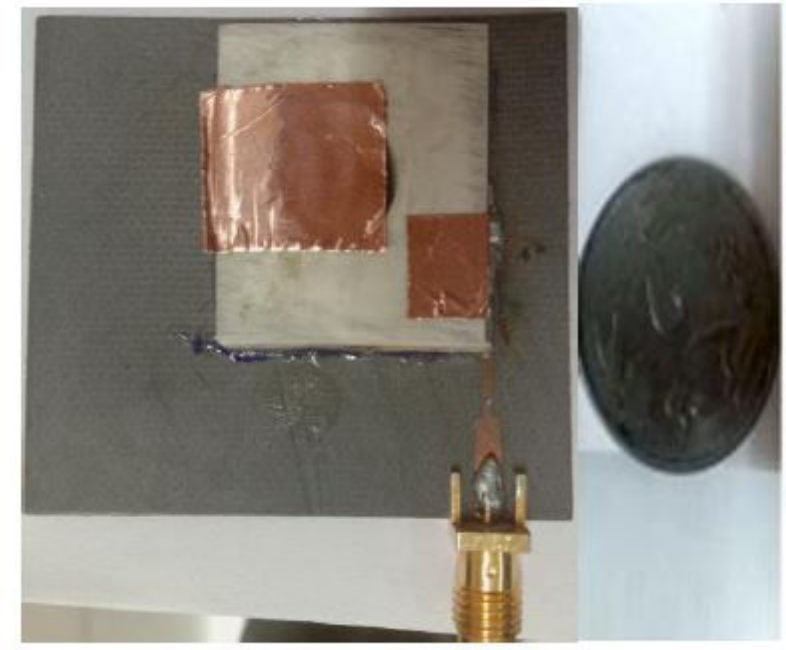

(a)

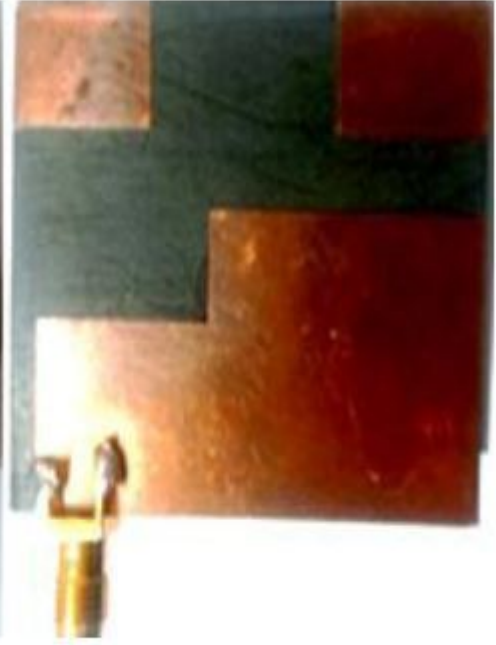

(b)

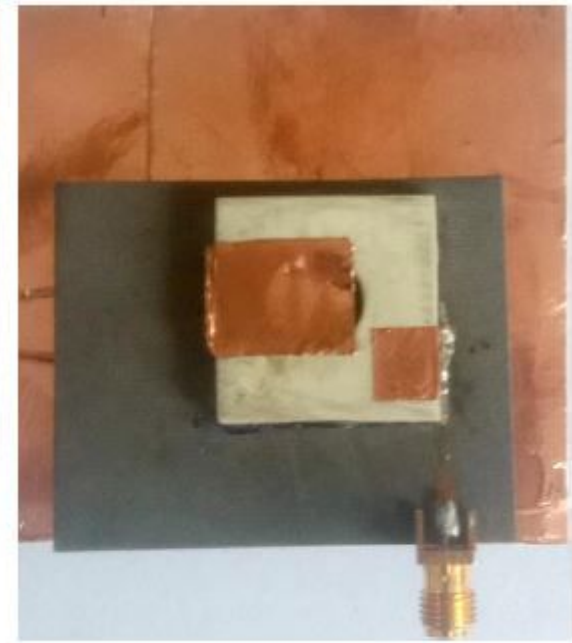

\section{Figure 7}

Snapshot of fabricated CPHDRA (a) Front view with MRPS (b) Back view (c) Front view with metallic reflector 


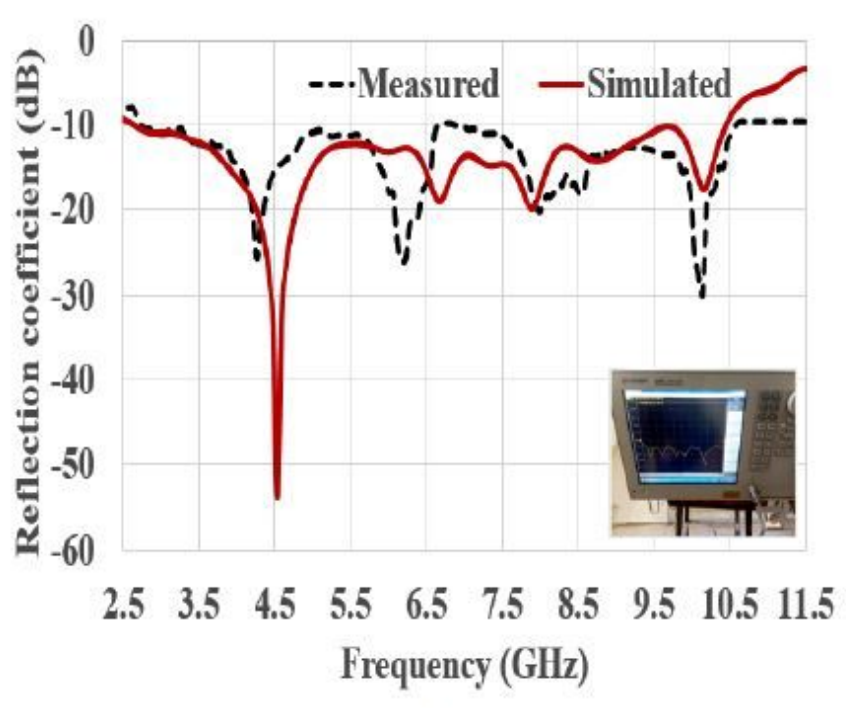

(a)

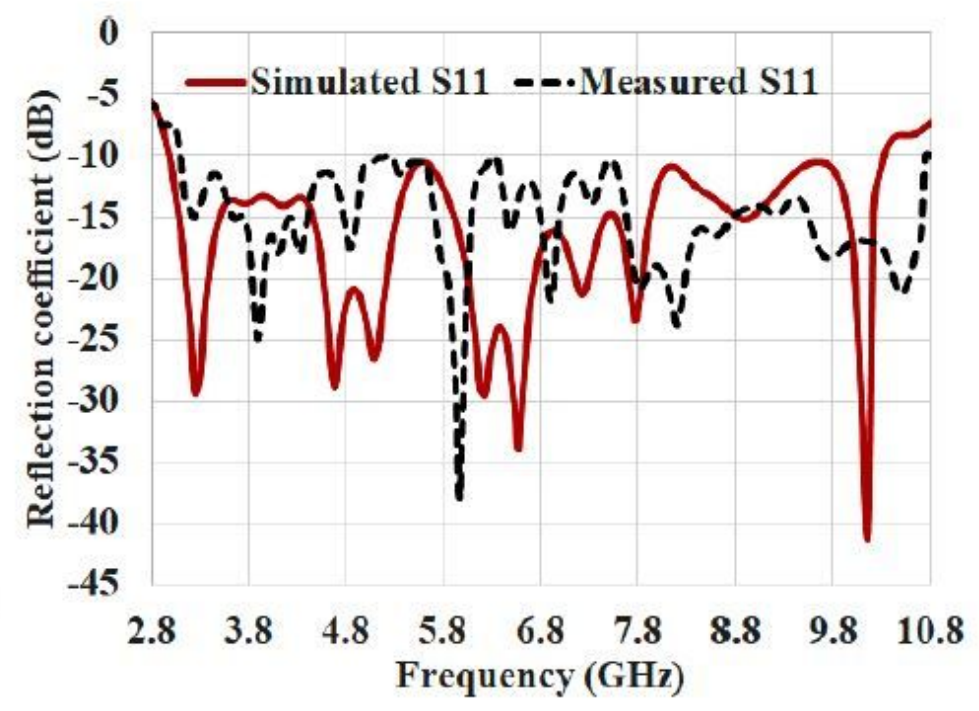

(b)

Figure 8

Simulated and measured S-parameter of proposed CPHDRA a. S11 without reflector b. S11 with reflector

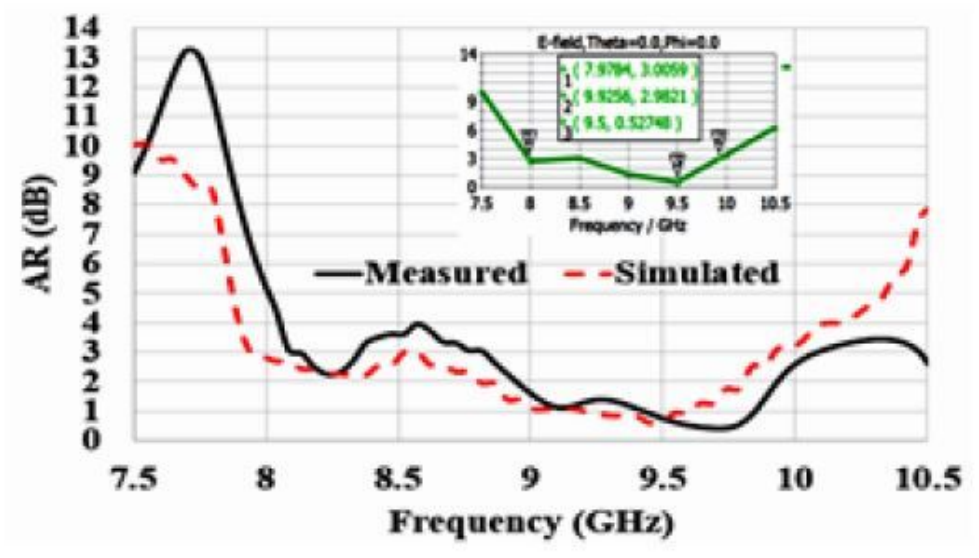

(a)

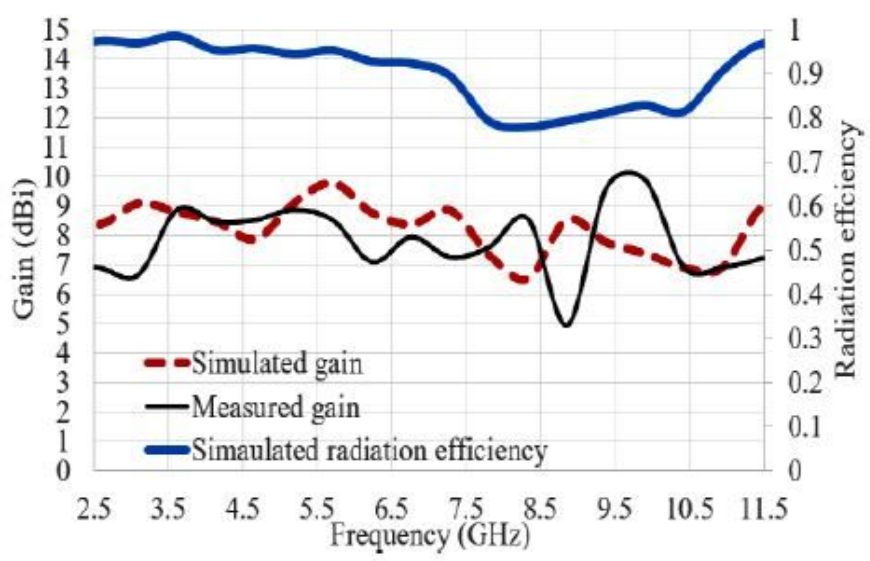

(b)

Figure 9

proposed CPHDRA a. axial ratio plot, b. Gain and simulated radiation efficiency 

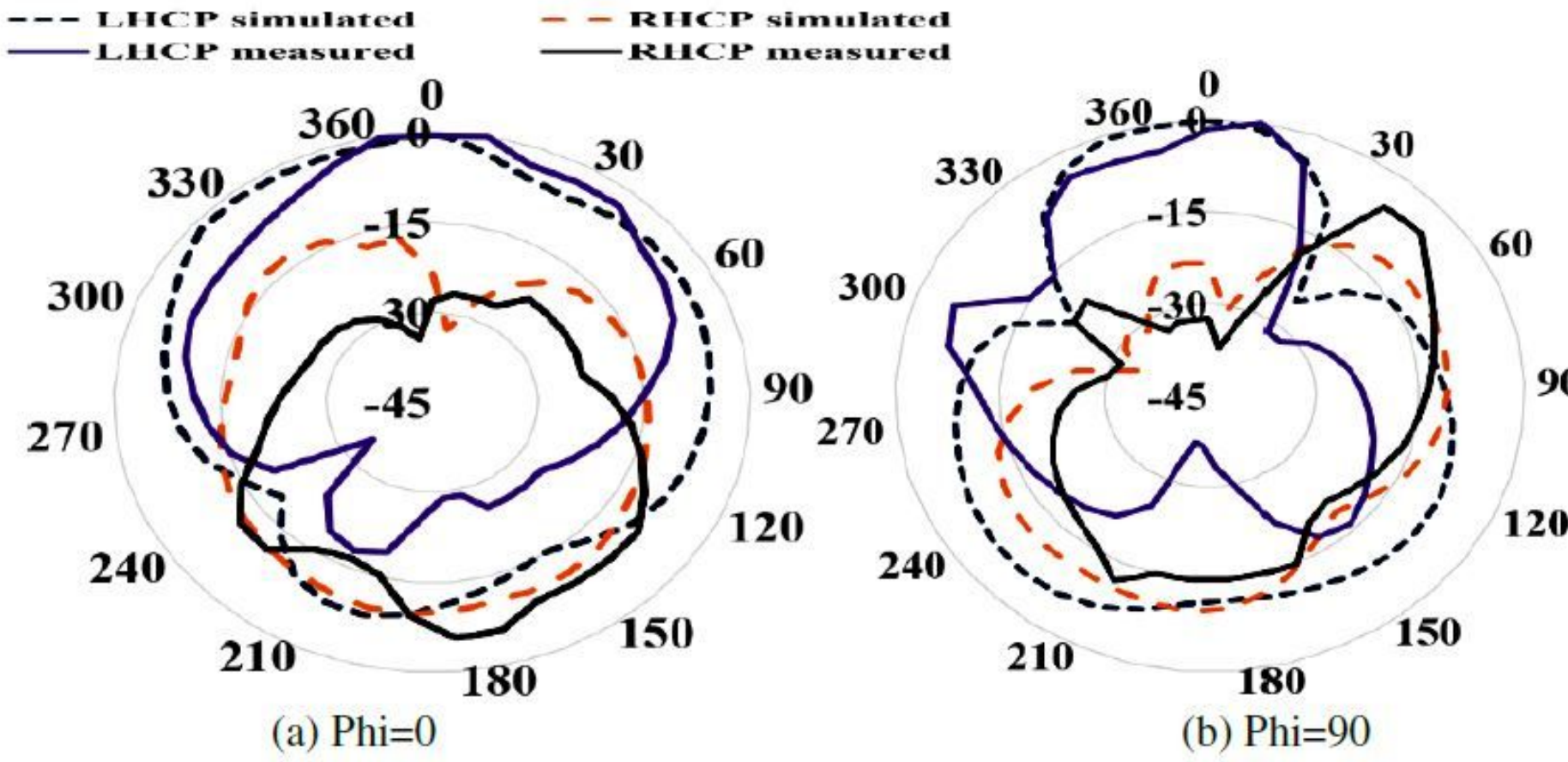

Figure 10

LHCP and RHCP pattern of antenna at $8.8 \mathrm{GHz}$

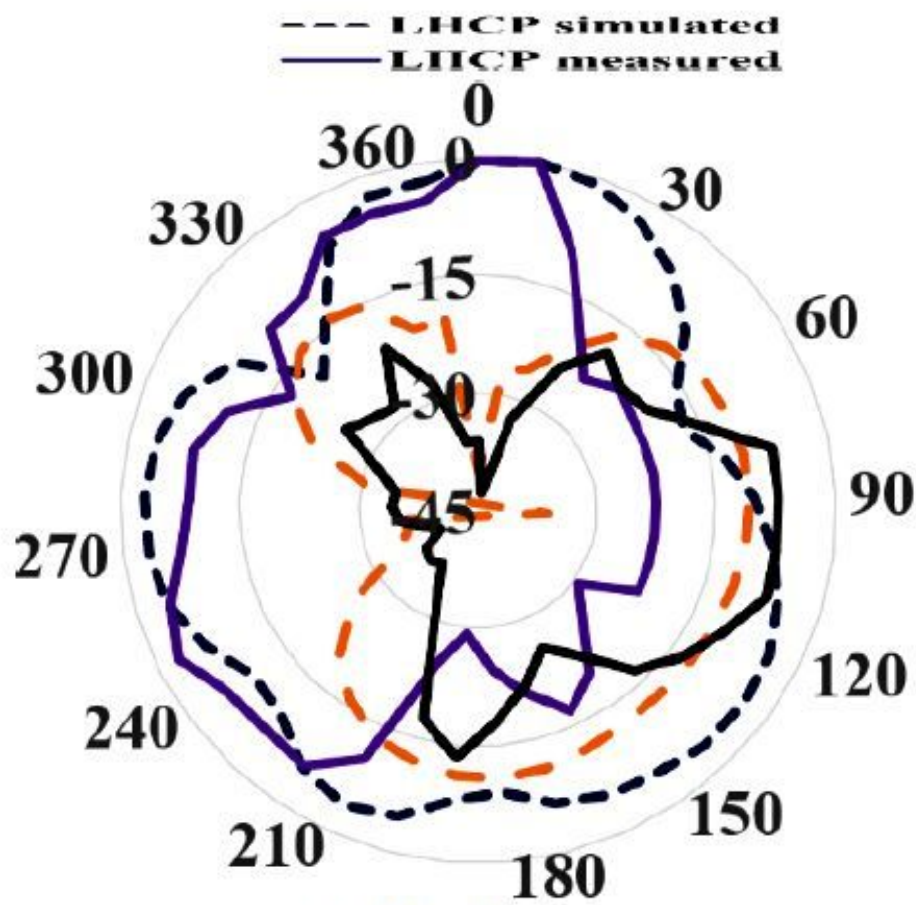

(a) $\mathrm{Phi}=0$

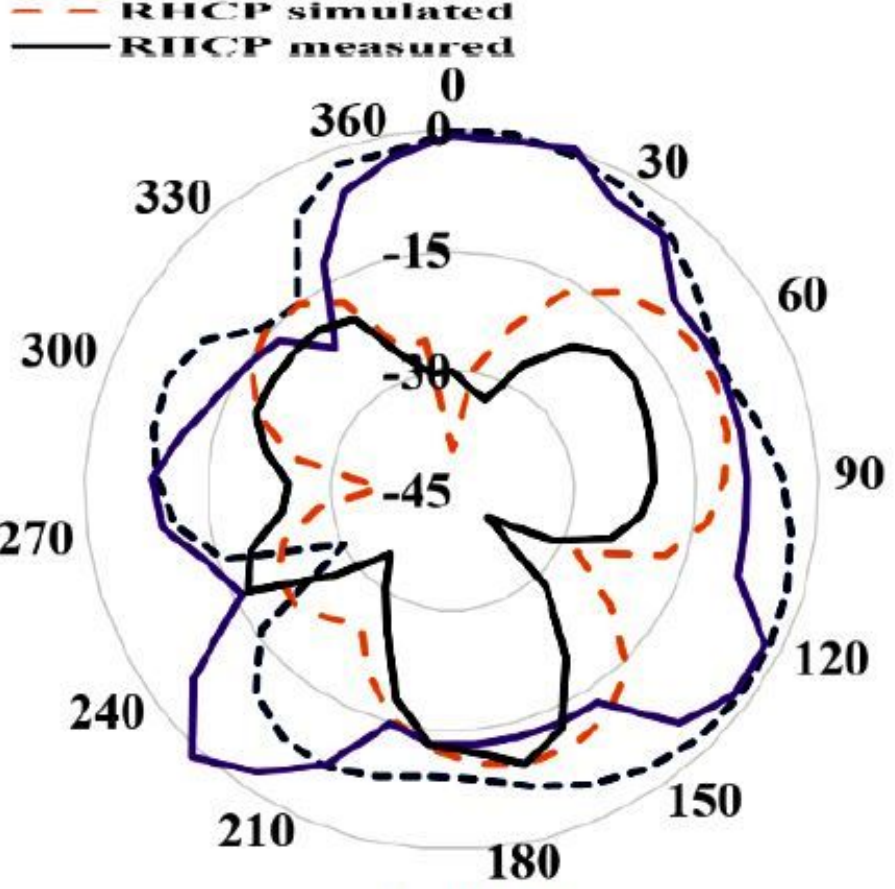

(b) $\mathrm{Phi}=90$

Figure 11

LHCP and RHCP pattern of antenna at $9.9 \mathrm{GHz}$ 